Portland State University

PDXScholar

1979

\title{
An Investigation of sexuality and life satisfaction of institutionalized aged
}

\author{
Karla M. Baur \\ Portland State University \\ Sarah E. Booth \\ Portland State University \\ Bayard J.K. Doane \\ Portland State University \\ JoAnna Henry \\ Portland State University \\ Judy Quade McArdle \\ Portland State University
}

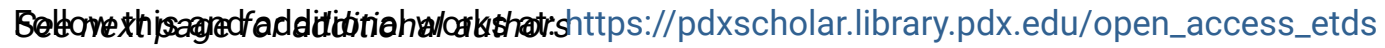

Part of the Gender and Sexuality Commons, and the Social Work Commons

Let us know how access to this document benefits you.

\section{Recommended Citation}

Baur, Karla M.; Booth, Sarah E.; Doane, Bayard J.K.; Henry, JoAnna; McArdle, Judy Quade; Nelson, Holly L.; Richman, James E.; Sutton, Jean Louise; Wildman, Suzan J.; Winter, Pamela K.; and Wood, Michael Taylor, "An Investigation of sexuality and life satisfaction of institutionalized aged" (1979). Dissertations and Theses. Paper 2862.

https://doi.org/10.15760/etd.2855

This Thesis is brought to you for free and open access. It has been accepted for inclusion in Dissertations and Theses by an authorized administrator of PDXScholar. Please contact us if we can make this document more accessible: pdxscholar@pdx.edu. 


\section{Author}

Karla M. Baur, Sarah E. Booth, Bayard J.K. Doane, JoAnna Henry, Judy Quade McArdle, Holly L. Nelson, James E. Richman, Jean Louise Sutton, Suzan J. Wildman, Pamela K. Winter, and Michael Taylor Wood 
AN INVESTIGATION OF SEXUALITY AND LIFE SATISFACTION

OF INSTITUTIONALIZED AGED

by

KARLA M. BAUR

SARAH E. BOOTH

JAMES E. RICHMAN

BAYARD J. K. DOANE

JEAN LOUISE SUTTON

JOANNA HENRY

SUZAN J. WILDMAN

JUDY QUADE MCARDLE

PAMELA K. WINTER

HOLLY L. NELSON

MICHAEL TAYLOR WOOD

A practicum submitted in partial fulfillment of the requirements for the degree of

MASTER OF SOCIAL WORK

Portland State University 


\section{ACKNOWLEDGEMENTS}

We wish to acknowledge the following people for their support and assistance during the preparation of this study. We are grateful to Carolyn and Leo Pavlov, Directors of the Restorative Care Center, and their staff and residents for allowing us to conduct our research within their facility. Likewise, we wish to thank Renee Alexander of the Institute on Aging for her assistance, with the life satisfaction questionnaire and Vicki Schmal1, Ph.D., for her encouragement and assistance in dealing with sexuality among older persons. Our special thanks go to our advisor, Kathy Willis, for her knowledge and constant support in the areas of research and human sexuality, and to Lewis Curtis, for helping us to locate a suitable facility for our study. 
TABLE OF CONTENTS

PAGE

ACKNOWLEDGEMENTS • • • • . . . . • . . . . . . . . . .

CHAPTER

I INTRODUCTION • . • . . . . . . . . . . . . . . 1

II INSTITUTIONS FOR THE AGED . . . . . . . . . . . . 5

Institutional Function and Definition . . . . . 5

Negative Impact of Institutionalization . . . . 8

Other Perspectives of Institutionalization . . . 12

III SEXUALITY IN THE AGING POPULATION • . . . . . . . . 16

Physiological Changes in Sex Organs . . . . . . 16

Females

Males

Impact of Physical Changes in Sexual

Functioning . . . . . . . . . . . . 20

Debilitating Physical Conditions Affecting

Sexual Behavior ............ 22

Attitudes Towards Sexuality in Aging Persons . . 24

IV THE CONCEPT OF LIFE SATISFACTION . . . . . . . . . 28

Definitions of Happiness . . . . . . . . . 28

Impact of Philosophical Antecedents on

Psychological Theories . . . . . . . 29

V THE HYPOTHESIS . . . . . . . . . . . . . . . 32 
VI OPERATIONALIZING THE CONCEPTS . . . . . . . . . . . 34

The Life Satisfaction Scale . . . . . . . 34

Definition of Sexual Activity . . . . . . . 37

Development of the Questionnaire . . . . . . 39

Non-Genital Physical Contact

Masturbation

Sexua1 Touching

Penile-Vaginal Intercourse

Orgasm

Gender of Sexual Partner

Past Frequency of Sexual Activity

Other Important Factors

VII THE PILOT STUDY . . . . . . . . . . . . . . . 46

Administration of the Questionnaire . . . . . 46

Subjects................... 46

Initial Contact and Subject Reaction . . . . . . 47

Interviewer Reaction . . . . . . . . . . . 47

Written Responses .............. 47

Conclusions: The Revised Questionnaire . . . . 47

VIII WEIGHTING THE QUESTIONS . . . . . . . . . . . . 49

IX THE STUDY . • . . . . . . . . . . . . . . . . . 52

Search for Subjects . . . . . . . . . 52

Setting . . . . . . . . . . . . . 55

Subjects . . . . . . . . . . . . 56

Equipment . . . . . . . . . . . . . . 56

Procedure . . . . . . . . . . . . . . 58

Results . . . . . . . . . . . . . . . 59

X DISCUSSTON . . . . . . . . . . . . . . . . 61 
CHAPTER

PAGE

XI CONCLUSION . . . . . . . . . . . . . . . . . 64

BIBLIOGRAPHY . . . . . . . . . . . . . . . . . . . . 67

APPENDIX A: LSIZ QUESTIONNAIRE . . . . . . . . . . . . 78

B : PRE-TEST SEXUALITY QUESTIONNAIRE . . . . . . . 79

C: FINAL FORM OF THE SEXUALITY QUESTIONNAIRE . . . . . 81

D: PERSONAL VIGNETTES . . . . . . . . . . . . 85

E: INFORMED CONSENT . . . . . . . . . . . . . 90 


\section{LIST OF TABLES}

TABLE

PAGE

I Research on the Impact of Institutionalization and Suggested Changes .............. 15

II Changes with Age in Sexual Response Patterns . . . . . 19

III Search for Subjects . . . . . . . . . . . . . 54

IV Demographic Characteristics of Respondents . . . . . . 57 
CHAPTER I

INTRODUCTION

A review of gerontological research reveals a dearth of information relating to the sexual activity of the aged and the degree to which this impacts upon overall life satisfaction. The goal of this study is to look at these issues in hopes of enabling those serving the aged, especially social workers, to better understand this aspect of their clients.

Demographic data indicates that each year about half a million Americans reach the age of 65. By the year 2000 it is predicted that $15 \%$ of the total American population will be comprised of the elderly. Although the number of persons within this age cohort is steadily increasing, it represents a forgotten minority whose needs remain unmet.

The definition of "elderly" has changed. In 1900 the average life expectancy was 47 years; today it is 70.4 years. Fully half of all older persons are over 73, and one million are 85 and over. In 1970 there were 106,441 centinarians (Butler, 1975). Of the half million people reaching 65 each year, $26 \%$ will experience institutionalization at least once before their deaths, and $8 \%$ of those will die in institutions. Although only $4.8 \%$ of the total population are in fact institutionalized at any one time, this $4.8 \%$ represents approximately one million people (Palmore, 1970). 
Even though everyone ages differently, the basic components associated with aging remain the same: loss, change, and adjustment. Significant losses include position in society, possessions, friends, and mates. These necessitate change and accompanying adjustments which become increasingly difficult with age.' Bereavement may be one of the most crucial concerns of the elderly and of those who are involved with them, either professionally or personally. (Shanes, 1962)

Any change is a reminder of the aging process, and these decrements can be frightening as predictors of things to come (Kalish, 1975, p. 58). Neither the process of aging nor the state of being old is pathological, strange or deviant except as the result of certain unpleasant occurences that tend to be age related, much as other unpleasant occurences are associated with the pre-school years or middle years of life. (ibid., p. 1)

An unpleasant occurence generally associated with aging begins with a change in a person's self-image: This process occurs when it is realized that youth, so highly valued by American society, has diminished. Physiological changes are paramount. There are more variations in biological and behavioral functioning in older persons than in younger persons. Changes in appearance, wrinkles, gray hair, are culturally defined as negative. Psychomotor performance levels decrease with age. The more notable physical changes include decrements in visual and auditory capacities (MacFarland, 1968 and Kalish, 1975), resulting in impaired communication and ensuing social isolation. The lens of the eye loses elasticity causing the farsightedness, common to most older people. Depth perception and pupil functioning also diminish with age. Hearing impairments affect $13 \%$ of individuals between 65 and 70, and 26\% of those 75 and older (Riley, 1968). Compounding these sensory deficits is a high incidence of dizziness which serves 
as a major cause of injury in older persons (Birren, 1964). Older persons experience an increase in illness, diseases and accidents, and a correspondingly lengthened recovery period. It is noted that the course of medical problems does not of ten change for the better and numerous adjustments must be made (Kalish, 1975).

In addition, pervasive cultural variables have had an enormous impact on the 65-and-above age cohort. Major factors of the 20th century which have been most directly influential include breakdown of familial ties leading to nuclear family constellations which serve to further isolate and alienate the very old. This breakdown has been facilitated by technological advancements, most noteably automation and mass media. One result of this process seems to be ageism, or discrimination against people because of their chronological age. These elderly persons have experienced industrialization, the Great Depression, and two World Wars. Currently they battle the spiraling cost of health care and severe inflation compounded by enforced early retirement and resultant income reduction. Most elderly state that their greatest need is money or goods and services which can be purchased with money (Kalish, 1975). The uncertainty of the times, dramatized by a rising crime rate where the elderly are most often victims, greatly contributes to the feelings of vulnerability so common to the aged and maximizes the sense of loss of security.

One concern of this study is sexuality among the aged, since every person, regardless of age, is a sexual being. Society, however, has been slow to recognize this fact and has not accepted sexual activity among the aged. Along with the lack of social sanctioning, elderly 
persons are very susceptible to the myriad of myths, half-truths, misinformation, and incomplete data which affect their attitudes toward sexuality. Furthermore, older persons are susceptible to negative stereotypes of themselves as sexual beings. However, the effect of actual sexual activity upon overall life satisfaction among the aged has yet to be determined. Because there has been no empirical evidence concerning this, the degree of relationship between sexual activity and life satisfaction remains unknown. Since human beings remain sexual throughout life, and a large proportion of the elderly are institutionalized, this study will focus attention on the relationship between life satisfaction and sexuality among the institutionalized aged. It is important for social workers to explore these concepts, as empirically validated knowledge can be used as guidelines for professional values and practice. 
CHAPTER II

INSTITUTIONS FOR THE AGED

INSTITUTIONAL FUNCTION AND DEFINITION

Institutions for the aged are designed and function as protective environments for those whose declining years are accompanied by physical, mental, economic, and social handicaps. Operating as isolated social communities, they serve as the primary caretakers and providers of our elderly. Acknowledging the existence of the varying degrees of organizational structure, restrictions, and residential expectations, the reality is that this society has relinquished its responsibility regarding the old to institutional bodies designated for that purpose.

Morton Lieberman (1969) conceptually defines institutions as "residential facilities providing one or more central services that meet some particular need of the client and/or society": He notes that such settings suggest indefinite residency and involve a major change from community living. Goffman (1960) developed a more analytical description and saw institutions as "symbolized by barriers to social intercourse with the outside". He states that institutionalization is an all-encompassing environment in that (1) all aspects of life are conducted in the same place under the same single authority; (2) all daily activities are carried out with the immediate company of others; (3) all daily activities are scheduled; and (4) all enforced activities are brought together as parts of a rational plan to fulfill the aims of 
the institution. Total institutionalization is an other-directed, self-perpetuating lifestyle. Townsend (1962) summarizes that people in institutions live communally with a minimum of privacy, subsist in a kind of defensive shell of isolation, experience restricted mobility with little access to society. They are oriented toward a system in which they are expected to submit, to be routinized, to forego selfdetermination. From this perspective, the general effect of institutionalization on older adults can be depersonalization of the individual, which is manifested as inertia, depression, and social isolation.

Pincus (1968) has a more comprehensive scheme for examining institutions. He sees institutional life as an end result of the complexity of several factors. He states that an institutional environment is created by the interrelationship of its particular physical characteristics, of its governing rules and regulations, and of its staff's attitudes and behavior. These factors co-exist to produce varying degrees of privacy, structure, resources, and integration with the outside community. These are salient components that determine a distinct psycho-social milieu which in turn yields predictable behavior in the institution's residents. Included in this institutional category are such environments as supervised geriatric residences, homes for the aged, nursing homes, domiciliaries, and mental hospitals. These settings differ by the level of care they offer, the nature of their residents and by the degree of social interaction and personal independence generated.

Bennett and Nahemow (1965) ranked these five kinds of institutions for the aged from those least institutionalized to those most institu- 
tionalized. Their evaluation listed them respectively as retirement communities, homes for the aged, domiciliaries, nursing homes, and mental hospitals. The aged adults most likely to be found in these institutions are generally white, female, older, and 1iving alone. Significant to the selection process are such factors as marital status, family relationships, financial resources, alternative living arrangements, and health status. Kraus, et. a1. (1976) compared long-term institutional residences with a matched group of community residences. It was found that individuals residing in the institutions were, on the average, older, had lower incomes, fewer spouses, more physical ailments, and less social involvement prior to institutionalization. Most elderly stated that the main reason for institutionalization was to avoid becoming an excessive burden to their families.

There are further differences among the institutions. Specifically, those in homes for the aged tend to have more resources; e.g., individual capability of awaiting placement, family impetus or money. Self-care and ambulatory skill are standard requirements for acceptance into homes for the aged. Therefore, these residents tend to be more physically and mentally intact, youthful, and are more resourceful than people found in other institutions. In contrast, the nursing home population is older and significantly more physically handicapped. They consist of people who are usually admitted as a result of a crisis, and are in need of skilled or intermediate nursing care. Nursing homes are viewed by the elderly as 'the end of the road'.

Historically, the mental hospital has accepted older persons not suitable for nursing homes because of problematic behaviors such as 
agitation, suicidal tendencies, aggression or paranoia. During the 1960 's and 1970's, older persons who were simply disoriented or confused were placed in nursing homes or community-based boarding homes. The more severely impaired continued to need psychiatric hospitalization.

In summary, there is differentiation of residents in various institutions. Those in old age homes are considered the 'nicest' and most capable; those in nursing homes are the most physically disabled; and those in state hospitals are the most severely mentally impaired.

\section{THE NEGATIVE IMPACT OF INSTITUTIONALIZATION}

Bennett and Nahemow (1965) analyzed social adjustment in institutions for the aged. They defined adjustment as the ability to fit oneself into an ongoing social situation and identified three hierarchical components of that process: social integration, evaluation, and conformity. They discovered, in accordance with the formation of their institutional hierarchy, that the negative impact of institutionalization lessened considerably as the opportunity for socialization and community involvement increased.

Nevertheless, there exists a commonly-held theory (Aldrich and Mendkoff, 1963; Blenker, 1967; Goldfarb, Shahinian and Turner, 1966; Jasnau, 1967; and Lieberman, 1961) that institutionalization has adverse effects upon the physical survival and psychological well-being of aged adults. Researchers have labeled the psychological effects as: 
...poor adjustment; depression and unhappiness; intellectual ineffectiveness because of decreased energy; negative selfimage; feelings of personal insignificance and impotency; and the view of the self as old. Following institutionalization and especially after relocation, residents tend to be docile, submissive, show a low range of interests and activities, and live in the past rather than in the future. They are withdrawn and unresponsive in relationship to others and feel increased anxiety which focuses on the feeling of death. (Lieberman, 1969)

Townsend (1962) in his comparison studies found that institutionalized groups seemed to have an impaired level of overall adjustment, reduced capacity for independent thought and action, a depressive mood tone, and problems involving self-esteem. Goldfarb (1959) and Pollack et. a1. (1967) both observed a display of negative self-image expressed verbally and non-verbally through crying and avoidance. These behaviors are characteristic of a widespread symptomology found in institutions for the aged. Halbfinger (1976) noted feelings of frustration, hopelessness and powerlessness in residents who had no one to talk to, and that the institution provided few supports for the development of sustaining friendships. In turn, residents did not form close relationships, did not exercise much self-determination and rather submitted to the orderly routine. The environment worked on the residents and residents in turn affected the environment.

The psycho-social elements associated with adjustment to institutionalization are cognitive functioning, body orientation, personality traits, time perspective, affect states, relations with people, and self-image. Lieberman, Prock, and Tobin (1968) made a cross-sectional study comparing three groups (institutionalized, community, and waiting 1ist) on these seven areas of functioning. Those in institutions had more disorientation to time and space; more disorganization in the area 
of cognitive functioning; showed more preoccupation with their body and issues relating to their body; were less constricted in their emotional responsiveness; and less anxious but just as depressed as those on the waiting list.

The effects of institutionalization on the health of older persons cannot be ignored. Rahe (1969) determined life changes and object losses affect the overall health status of a person. Therefore, involuntary relocation and institutionalization as well as the anticipation of these two events have enormous ramifications for affecting the physical survival of older persons. Those persons institutionalized are less physically able than those non-institutionalized, and those experiencing relocation often become ill, are hospitalized, and/or experience activity restrictions (Lawton and Yaffe, 1967; Lieberman, Prock and Tobin, 1968). Bourestom and Tars (1974) noted that following relocation, residents become more pessimistic about their state of health, stopped participating in psycho-social activities, grew less active with both staff and fellow patients, and felt staff members were not interested in them. Miller and Lieberman (1965) noted more occurrences of confusion, memory defects and bizarre behavior following institutionalization, especially within the first two months of adjustment. The Killian (1970) and Aldrich (1964) studies found that transfer from one institution to another increased mortality. They also learned that patients whose adjustment to institutionalization was satisfactory or angry were more likely to survive relocation than those who had been neurotic, depressed, or psychotic. In addition, those whose reactions to impending relocation were judged to be philosophical, angry, anxious, 
or regressed were more likely to survive than those who were depressed, denying or psychoric. Studies (Costello and Tanaka, 1961; Tobin, 1968) described high mortality of aged subjects within one year or less of institutionalization. Particularly high rates were found among men, the very old, the individuals with poor health, severe brain dysfunction, and those characterized by passivity. In 1970, Killian studied a group of deinstitutionalized older persons. The highest mortality rates were found in the groups forced to relocate in environments most alien to their prior institutional experiences. The lowest rate was among the group that stayed in the original setting. As can be expected, the older, non-ambulatory members had the highest mortality rates in any of the groups.

Institutionalization is a complex process and it becomes very difficult on an empirical basis to isolate what differences can be attributed to the characteristics of institutional life alone or to some other variable. Lieberman, Prock, and Tobin (1968) felt that data should be examined at three points in time to adequately reflect the process and what happens: Phase $I$, when the person first seriously considers moving into an institution; Phase II, just before and just after entrance; Phase III, after a period of adjustment to the institution. This theory supports the idea that a longitudinal study would be more appropriate to the situation than a cross-sectional one. However, most of the research has been cross-sectional in nature and involves comparing groups of people living in the institutions to both those in the community and those in transition. 


\section{OTHER PERSPECTIVES OF INSTITUTIONALIZATION}

Other researchers have indicated that institutionalization does not necessarily have to have detrimental effects on all older persons. Linkages have been established between external institutional elements and specific behaviors. Reingold and Dobrof (1965) found that staff valued and responded differentially to residents which resulted in both an increase in valued behavior and a decrease in undesired behavior. Mercer (1978) found a high negative correlation between hopelessness and activity, especially if the activity was designed to increase control and choice. Halbfinger (1976) identified institutionalization as being beneficial to the resident when $s /$ he was offered activities that most closely resembled a pre-institutional experience, and when relationships with staff were mutually gratifying. Donahue, Hunter, and Coons (1953) showed that an increase in formal activities as well as an expectation for participation produced more social relationships and a greater sense of overall life satisfaction. Silverstone and Wynter (1975) also discovered a richer level of social adjustment occurred when members of the opposite sex were introduced to previously segregated floors in a home for the aged. Offering the opportunity for male-female interaction to the institutionalized elderly offset shrinkage in their social life space. Donahue, Coons, and Gotterman (1969) found that a supportive milieu which provided both means and motivation for the residents to use their mental, social and physical abilities produced pride, selfconfidence, and higher levels of independent functionings. Anderson (1967) found that interaction and self-esteem are more closely associated than are institutionalization and self-esteem. She proposed that 
institutionalization can increase the quantity and quality of interaction and therefore raise self-esteem, particularly if a person has been isolated. Oberleder (1976) discussed the negative behaviors and attitudes associated with institutionalization, but spoke of them as part of the resident's normal regression under stress. He considered these reactions as appropriate to the continuing internal and external changes with which older people must cope, the demands of the new life roles they must fulfill in the institutions, and the reality that they are awaiting possible illness and death.

Different institutional environments produce varying demands resulting in a myriad of adaptive personality types. Turner, Tobin, and Lieberman (1972) discovered that those people possessing personality traits already congruent with an institution's expectations were viewed as better adjusted and more acceptable than those with non-corresponding characteristics. The greater the degree of rigidity within an institution, the more negative is the impact on the individual. Thus negativity must be viewed correspondingly with institutional milieu and procedure.

In a similar vein, K.F. Jasnau (1967) examined elements which affect the mortality rates of older persons. These include (a) how the institutionalization or relocation is carried out; (b) the degree of choice that the patients have in the change; (c) the adequacy of preparation by support people; and (d) the meaning of "institutionalization" for the individual. There tends to be an increased mortality rate if the change is involuntary, if there is little preparation, and if institutionalization is dreaded. 
The variable of self-selection is also an important consideration when measuring negative impact. The person who applies to an institution is 1ikely to be incapacitated. Concommitant with the radical environmental changes are adverse effects attributed to some aspect of the institutionalization, such as poor diet, infections, poor medical care, and sensory deprivation. Kasl (1972) mentions that it is not possible to disentangle (a) self-selection from effects of institutionalization; (b) effects of moving into an institution from effects of living in it; and (c) differential survival from effects of the institution.

The significance of institutional life is far-reaching in its influence. (See Table I) In addition to the effects upon the physical well-being of residents, sexual functioning is also affected by the process of institutionalization itself. We will now look more closely at sexual functioning in the aged. 


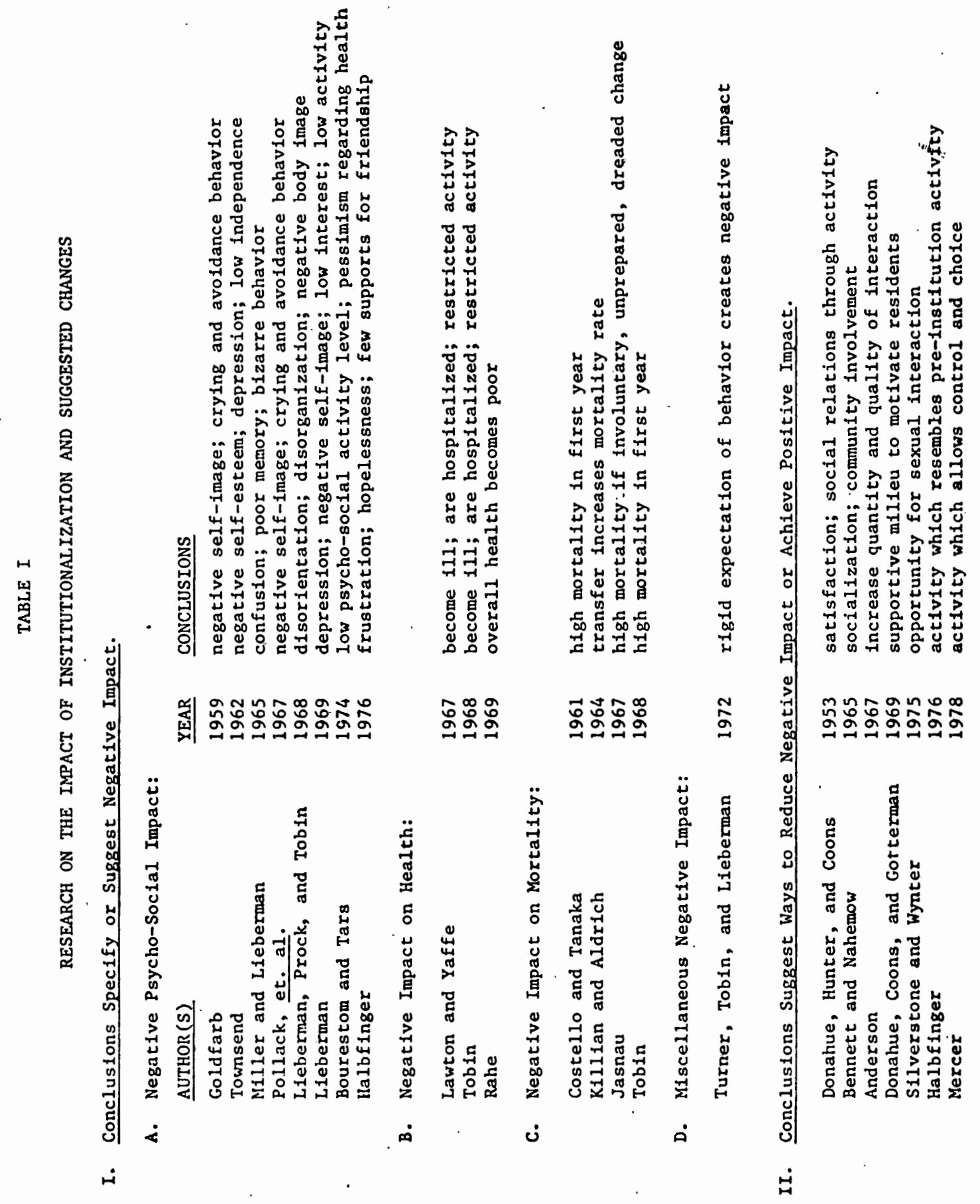


TABLE II

CHANGES WITH AGE IN SEXUAL RESPONSE PATTERNS*

\begin{tabular}{|c|c|c|}
\hline & rounger Wonien & Otdor IVomen \\
\hline \multirow[t]{2}{*}{ Breasis } & Aippio erection & Same \\
\hline & $\begin{array}{l}\text { Increase in size, areo- } \\
\text { isr engorgement, llush } \\
\text { prior to orgasm }\end{array}$ & $\begin{array}{l}\text { Intensity of reactions } \\
\text { diminisitus }\end{array}$ \\
\hline
\end{tabular}

Sex flush Vasocongestive? skin Diminishes response to terision

Myotonia Muscular tension in- Response diminishes creases

\begin{tabular}{|c|c|}
\hline $\begin{array}{l}\text { Linary } \\
\text { System }\end{array}$ & $\begin{array}{l}\text { Ainimal distention of } \\
\text { external urinary mea. } \\
\text { is during orgasm }\end{array}$ \\
\hline Rectum & $\begin{array}{l}\text { Pectal sphincter con- } \\
\text { tractions with orgasm }\end{array}$ \\
\hline Clitoris & $\begin{array}{l}\text { H.gh degree of } \\
\text { responsivity }\end{array}$ \\
\hline $\begin{array}{l}\text { Mij,or } \\
\text { Labla }\end{array}$ & $\begin{array}{l}\text { F'stlen, separate, and } \\
\text { cievate with increased } \\
\text { sexual tension }\end{array}$ \\
\hline $\begin{array}{l}\text { Minor } \\
\text { Lobia }\end{array}$ & $\begin{array}{l}\text { Vasocorigestivu thick- } \\
\text { enıng: color change } \\
\text { ifom cardinal-red to } \\
\text { turgundy-wine before } \\
\text { o-gasm }\end{array}$ \\
\hline
\end{tabular}

Bartholin's Srall amount of mu-

Glands coid secrotion during plateau

Vagina

yalls well-corrugated, Walls tissue-paper-

tr..ckened, redJish.

purple appearance;

vaçinal lubrication

within $10-30$ seconds

c! stimulation

Uterus

\begin{tabular}{|c|c|c|}
\hline & rounger filen & Older Men \\
\hline Breasts & Nipple erection & Diminisher \\
\hline Myotonia & $\begin{array}{l}\text { Increased muscular } \\
\text { tension; involuntary } \\
\text { muscular contrac- } \\
\text { tions }\end{array}$ & $\begin{array}{l}\text { Responses may } \\
\text { diminish }\end{array}$ \\
\hline Rectum & $\begin{array}{l}\text { Rectal sphincter } \\
\text { contractions during } \\
\text { orgasm }\end{array}$ & Decrease it trequoncy \\
\hline Penis & $\begin{array}{l}\text { Erection develops } \\
\text { within 3-5 seconds of } \\
\text { stimulation: full erec- } \\
\text { tion early in cycle }\end{array}$ & $\begin{array}{l}\text { Ercction takes } 2-3 \\
\text { times longer over } 50 \text {; } \\
\text { full erection not at- } \\
\text { tained until immedia. } \\
\text { tely prior to orgasm }\end{array}$ \\
\hline
\end{tabular}

Ejaculatory control varies

May attain and partially lose full erec.

tion, several times during cycle

Color change of Diminished or absent glans penis

Forceful ejaculation: Force diminishes; expulsive contrac- sensual experience tions during orgasm may be recuced

Refractory phase Prolonged refractory variable

phase after orgasm

before ne, t erection

rapid perile

detumescence

Ejaculation Two-stage, well-dil- Single-stage expulsion lerentiated process of seminal fluid
Orgasmic platiorm

(swelling of outer vagi-

na) develops during

plateau, constricting

vagina

Contractions (5-E) of Number of contrac.

platform during or- tions cecreases

gasm

During resolution, slow Rapic collapse

collapse of exoanded

portion of vagina

Prostatic contractions

Awareness of fluid emission and pressure

Scrotum

Scrotal folding pat

terns obliterated with sexual tension

Testes Testicutar elevation in late excitement or early plateau; increase in size

Testicular descent during resolution

Not clinically obvious

May experience seep. age rather than expul. sion; fewver and less... able sperm than younger rien

Response diminishes

Diminshed response

Reacion delayed and marked

Expulsive coniractions Decrease in number (3-5) with orgasm

* (from Nasters and Johnson, 1966) 
IMPACT OF PHYSICAL CHANGES ON SEXUAL FUNCTIONING

The sexual behavior of men and women over the age of sixty years has often been misunderstood, stereotyped, and/or ignored. Although there is not very much information about the sexual behavior of older adults, the research from the last 25 years indicate that people over sixty do have sexual desires, express themselves in sexual activities and are influenced in those activities by their personal health, social conditions, and type of previous sexual activity in younger years. Kinsey $(1948,1953)$ indicated people over the age of sixty are capable of continued sexual activity. Masters and Johnson (1966) also found that older men and women are still physically capable of intercourse and sexual desire. Verwoerdt, et. al. (1969) concluded that many physical and psychological factors alter patterns of sexual activity during the aging process, however. Specifically, 1) elderly men differ markedly from elderly women in reported sexual behavior; 2) sexual activity of elderly women is greatly dependent on whether or not there is a socially-approved partner available; 3 ) declining sexual activity and interest were common, but patterns of stable as well as increasing activity also occurred.

Pfeiffer and Davis (1972) identified the determinants of sexual behavior in middle and old age. Most notably, high sexual activity in middle years positively correlated with continued sexual activity throughout life. Variables that influence the sexual behavior of men are past sexual experience, age, health factors, and social class. Those factors which influence women are marital status, age, and degree 
of enjoyment derived from prior sexual experience. The availability of a socially-approved partner for a woman is an important determinant of her sexual activity (Verwoerdt, et. al., 1969). Note that sexual activity was determined by frequency of intercourse and interest in sex. Questions that dealt with other forms of sexual activity were not included in these surveys. Pfeiffer determined that approximately 80 per cent of the group are still sexually active. For men aged 78 or older 1 of 4 is still regularly sexually active. DeNicola and Peruzza (1974) found that marital status and health are also important determinants of sexual activity into old age. In both of these studies, sexual satisfaction was not limited to frequency of intercourse in the elderly persons questioned. According to West (1975), aged persons' sexual activity included fondling, carressing, and oral contact. It was stated that these activities often would not lead to orgasm, but still provided pleasure and release from tension. In a study (DeNicola and Peruzza, 1974) which did not distinguish between males and females, it was found that previous satisfaction in younger years tended to determine satisfaction after age sixty. He noted that some men would prefer oral-genital sex but would often not ask their wives to participate. Dean (1974) believes that the aged need not feel that sexual activity be confined to intercourse.

Elderly people who have sexual desire should be able to achieve fulfillment through any modified physical activity, reflective of their abilities and circumstances that would satisfy both partners. 
DEBILITATING PHYSICAL CONDITIONS AFFECTING SEXUAL BEHAVIORS

There are a variety of physical conditions which adversely affect the sexual functioning of many elderly persons. These conditions are often compounded by a number of misconceptions that can lead to either physical and/or psychological sexual dysfunction.

Heart attack can lead to impotency for both physical and psychological reasons. The fear of inducing another coronary and risking death is the most common and understandable reason for avoiding sex. Yet the incidence of death during intercourse is estimated at less than one per cent of sudden coronary deaths. Studies have indicated that the sex act, on the average, takes ten to fifteen minutes, and utilizes the oxygen equivalent of climbing one or two flights of stairs. Most physicians recommend a recuperative period of eight to fourteen weeks following an attack to allow for adequate healing before resuming sexual activity.

Episodes of congestive heart failure are also commonly called heart attacks. They can be treated with digitalis, diurectics, and diet; and sexual relations are again possible. The recovery period is generally two to three weeks. Moderate exercise is recommended to reduce the possibilities of another attack. Sexual activity provides this exercise as well as producing exhilaration, release of tension, and a sense of well-being.

Strokes (cardiovascular accidents) do not directly impact on sexuality or sexual activity. However, when paralysis has occurred, it may be necessary to chose appropriate sexual positions to compensate for the diminished mobility (Butler and Lewis, 1976). 
Vascular diseases can impair the sexual response to the extent that it impacts upon vascular engorgement and muscular contractions. This can occur with thrombosis of veins or arteries of the penis, leukemia, and sickle cell disorders, among other things. The condition impairs erection only; ejaculation and libido remain intact. This occurs because of the interference with penile blood supply, and can generally be surgically corrected (Kaplan, 1974).

Hypertension (high blood pressure) does not directly affect erection. However, many forms of anti-hypertension medication can cause impotency by impairing the neurovascular reflexes. When the medication is discontinued, or changed, the potency returns.

Diabetes is common in later life. It is one of the few illnesses which can directly cause chronic impotency in men. Impotency occurs two to five times as often in diabetics as in the general population. In diabetes there can be depression of the central nervous system, general debility, lower androgen levels, and depression, all of which may decrease libido and impair arousal (Kaplan, 1974). When the disease has been poorly regulated, there is a good possibility that proper regulation will increase potency. However, when impotency occurs in well controlled diabetes, it may be permanent (Butler and Lewis, 1976).

The form of arthritis that most of ten affects the aged is Osteoarthritis. It is usually mild, not inflammatory and rarely interferes with sex. Rheumatoid arthritis may cause pain during sexual activity, although there is evidence that suggests regular sexual activity helps to relieve the arthritic condition. This is due to adrenal gland production of the hormone cortisone and the physical activity involved. 
Backache is common among older people. This is often caused by a sudden use of back muscles in a generally inactive person. Sexual activity itself is often an excellent form of exercise therapy for the back, stomach, and pelvic muscles and can do much to reduce back pain when undertaken regularly (Butler and Lewis, 1976).

Anemia has been found to some degree in one out of four people over sixty. It is a common cause of fatigue and consequent reduction of sexual activity. Since anemia is a symptom of a number of diseases, comprehensive medical treatment is necessary and follow-up is important. Often improved diet and vitamins are all that is necessary to restore both energy and sexual activity (Butler and Lewis, 1976).

Any condition which either causes pain on intercourse or interferes with intromission or stimulation may affect the sexual response adversely. Kaplan (1974) reports that estimates regarding the number of sexually dysfunctional patients who demonstrate some organic component range from 3 to 20 percent. Obviously, physical factors may play a role in sexual complaints, and decreased sexual activity. Knowledge of precipitating factors, and regular treatment can aid the aging person in maintaining sexual activity. Also, influential in the maintenance of sexual activity are the attitudinal beliefs coherent in both individuals and society as a whole.

\section{ATTITUDES TOWARD SEXUALITY IN AGED PERSONS}

There is a degree of self-fulfilling prophecy in the attitudes of society that contribute to age-role expectations of non-sexuality among the aged. Neugarten (1965) stated that there is an age-role identity 
as well as a sex-role identity. At each age people are expected to behave in "appropriate" ways. The expectation of society toward the aging individual was to conform to social image and dress, not seek pleasure in sex, avoid scandal or ridicule, and believe in the myth of lost sexuality with age (Glover, 1975). Grown children who were cautioned about sex and were taught to regard it as dirty, reverse the process when they become parents and condemn sex in their elders (Dean, 1966). Cleveland (1976) delineated attitudes toward aging sexuality that she referred to as the 'traditional' norms of behavior:

Sex is for procreation and aging couples are not childbearing couples. Sexual tension and need for sexual outlet are highest during youth and radically decline with old age; therefore, aging married couples physiologically don't need sex. Body organs are at peak health during youth and healthy sex is satisfying sex; because people are less healthy in later life, sex will be less satisfying. Sexual tension is built on physical attractiveness; to be old is to be ugly and ugly people can't inspire sexual tension in others. Romantic love can occur among the young and sex without romantic love is not quite normal. (p. 234)

Spinazzola (1975) stated that the general public feels that older people do not have sexual desires or a need for sexual expression and if they do, it is improper for them to do anything about it. As a sidelight of a more comprehensive study, Golge and Kogan (1959) found that a group of students answering a sentence completion test question "Sex for most old people....", 92.9\% replied that for most old people sex was negligible or unimportant; while in the group that answered the question "Sex for most people....", only $4.9 \%$ of the respondents regarded sex as negligible or unimportant. Feigenbaum (1967) mentioned the lack of factual data regarding the sexual habits and attitudes of the aged. He added that the elderly are both confused and interested in 
obtaining information regarding the sexual norms of the geriatric population. Long (1976) stated that the belief that sex is somehow "dirty" and not to be enjoyed or needed is often Biblically founded. Winter (1973) observed that women sometimes lose their desire for sex after menopause because sex is linked in their minds with the Biblical injunction to "be fruitful and multiply". Christenson and Gagnon (1965) reported that church attendance has an inverse relationship to coital and masturbatory activity for the married and unmarried.

Pfeiffer (1974) wrote that our cultural attitudinal taboo is related on a more unconscious level to feelings regarding sexual expression in our parent generation. It is noted that aging patients, to a significant degree, evoke the unconscious reminder of our own parents and, as such, we may wish to avoid dealing with the sexuality of elderly people.

LaTorre and Kear (1977) assessed attitudes toward sexual behavior in the aged residents of a nursing home. Contrary to their hypothesis, while staff members were no more negative towards sex in the aged than towards sex in younger people, student respondents working in the nursing home were less negative than the permanent staff members toward sex in general. Merritt, et. al. (1975) reported both greater and less education to be associated with negative sexual attitudes.

Snyder and Spreitzer (1976) investigated attitudes of the aged toward premarital sexual relations, extramarital sexual relations, and homosexuality. Their findings indicate that older people tend to hold disapproving attitudes toward these non-traditional sexual behaviors; however, there is still variation of activities among older people. 
It could, therefore, be hypothesized that the societal prejudices and oppression experienced by homosexual individuals of all ages is experienced even more severly by older homosexuals and may have a negative effect on life satisfaction. Generalizations must be qualified in terms of levels of health, education, social class, occupation, church attendance, and marital status. The pattern of homogeneity within the variations should not be assumed.

Traditional cultural attitudes imply a continual decline in sexual interactions until disuse and disinterest bring about a full cessation of sexual activity. Sanders (1976) states "...the impact of societal attitudes influences the aging to repress and deny their sexual feelings" (p. 505). Many authors (Masters and Johnson, 1966; Pfeiffer, 1974; Sanders, 1976) have written that the denial of sexuality in older years damages the aging individuals sex-life potential, selfimage, and self-esteem. It has been stated (Masters and Johnson, 1966) that "ignorance is one of the greatest deterrents to effective sexual functioning in all ages, but its been most damaging to the aging" (p. 316). Older people want and need information about sexuality and the sexual norms of their peers. They often tend to withdraw from social interaction because they simply do not know what is normative for their age group (Burnside, 1976; Sanders, 1976).

It is apparent that in spite of negative attitudes towards sexuality in older persons, sexual activity does occur, but the importance of this activity upon life satisfaction has not yet been determined. An examination of the concept of life satisfaction is needed before its relationship to sexual activity can be explored. 
CHAPTER IV

THE CONCEPT OF LIFE SATISFACTION

DEFINITIONS OF HAPPINESS

The concept of life satisfaction assumes "happiness" exists and is a basic value of life. Although the concept itself is elusive and difficult to define precisely, the goal of this study is to create an operational definition of life satisfaction. Philosophers, beginning with Plato and Aristotle and continuing through the present day have engaged in controversy over understanding the concept of happiness. This chapter highlights the notable theories of happiness as they relate to the concept of life satisfaction employed in this research.

Happiness, as defined by Aristotle, is the highest good and is relative to each individual. Man is motivated above all else to pursue those activities which are pleasurable and expected to bring happiness. Intimately intertwined with Aristotilian logic is Plato's conception of happiness which emphasizes virtue. Virtue necessarily results in happiness. Similar to Platonism, the essence of Stoicism also centers around the concept of virtue although the degrees between virtue and vice are eliminated: man is either all good or all bad. These theories incorporate the notion that happiness is attainable, and specify, to some degree, what an individual must be, have, or do to be happy. Thus, a person may examine himself relative to these ideals and take an active stance towards attaining happiness. 
Kant highlights the dualism between virtue and happiness: human beings have a natural desire for pleasure, and at the same time, are functioning within the constraints of moral reasoning. Thus, the activity from which one derives pleasure may conflict with the activity which morality dictates. Kant believes that because of this permanent conflict, happiness cannot be attained. Hegel, however, diverges from Kant's belief by asserting that this conflict can be resolved through learning and happiness then becomes attainable.

Hedonists maintain that the individual pursues pleasure and avoids pain. A derivative of hedonism is the Utilitarian concept which states that moral action is the greatest happiness of the greatest number. The motivation for action becomes dualistic: while the individual seeks personal pleasure, he is also concerned with the happiness of the greater community. Within the framework of self-realization, happiness is seen to be both moral attainment and fulfillment of individual potential. Rather than seen in opposition, reason and desire are fused: every desire has its rationale, every reason which leads to action must have a desire. Inherent in self-realization theory is the concept of selfpreservation. Nothing can be attained unless the self is preserved.

IMPACT OF PHILOSOPHICAL ANTECEDENTS ON PSYCHOLOGICAL THEORIES

The impact of the philosophical antecedents of the concept of life satisfaction can be found in several current psychological theories. The influence of Hedonism and the pleasure-pain principle is found in the thinking of Freud, Erikson, and Skinner. Freud claims that happiness comes from the satisfaction of pent-up needs which have reached 
great intensity. (Kretch and Crutchfield, 1966) The external society places demands on the individual and man must repress inner drives to function within the constraints of society. In view of that, s/he will never attain true happiness. Nevertheless, man is internally motivated to avoid pain and pursue pleasure. Erikson, a strong proponent of Freudian thought, believes that happiness is attainable even in the face of the necessity of cultural repression. His view of the function of achieving "integrity" in old age can be thought of as a part of life satisfaction (Kretch and Crutchfield, 1966). In examining B.F. Skinner's contributions, while he is not concerned with the inner beliefs or subjective values of observed subjects, the influence of the pleasure principle is clear. Skinner observes that while pain is a temporary deterrent to activity, unless extreme, it will not result in avoidance of the activity itself. Rather, a more predictable human response is to engage in those activities which result in positive environmental reinforcement, i.e., pleasure (Skinner, 1953).

Personality theories have emerged which emphasized more positive satisfying aspects of life and were based on the earlier concepts of self-realization. Maslow has perhaps most adequately expanded upon the construct of self-realization, defined as the basic tendency toward making actual what is potential within the self. He emphasizes gratification, joy, curiosity, and creativity. Personality development, when not disrupted by dysfunctional interactions and occurrences, is seen as a gradual process of the "unfolding" of essential needs and attributes of human nature. Individuals pass through a sequential series of stages seeking higher and higher levels of organization. 
Crucial to the construct is the idea that the lower needs must be adequately satisfied if the developmental process is to proceed toward the maximum emergence of the personality. (Kretch and Crutchfield, 1966) Thus, inherent in the concept of full personality development is the basic idea of life satisfaction on a variety of levels.

While all of these perspectives on life satisfaction have been used at one time or another to define happiness, the most useful definition with an aging population is one which is consistent with known factors regarding aging, reflective of the existing culture, and takes into account variability inherent in the over 65 population. The phenomenological approach, exemplified by Maslow, perhaps best fits since it reflects a more flexible definition of life satisfaction. 
CHAPTER V

THE HYPOTHESIS

Research is a forerunner of social change. Recognizing the elderly are an increasing population within our society and that many of these individuals either are or will be institutionalized, this study addresses the issues of sexuality and life satisfaction among institutionalized aged.

Sexuality is a basic drive throughout life; however, it of ten has remained unacknowledged in the lives of older persons. It is known that many factors contribute to an individual's overall life satisfaction, including sexuality. Yet to date, there has been little objective evidence linking the concept of life satisfaction to sexual activity among an elderly population.

Basically, the question this study seeks to address is whether sexual activity makes any difference in the overall life satisfaction of the institutionalized aged. Because life satisfaction can be assessed phenomenologically, while sexual activity can be linked to a hedonistic position, the underlying philosophical issue being addressed is to what extent hedonism is reflected in a phenomenological approach to life.

The evidence accumulated thus far shows that sexual behaviors occur in spite of negative stereotypes about sex in the aging population and continue to provide avenues for comfort and contact for participants. 
33

Because sexual activity occurs even in the face of opposing social

forces, it is hypothesized that among the institutionalized aged, there is a strong and positive relationship between sexual activity and overall life satisfaction.

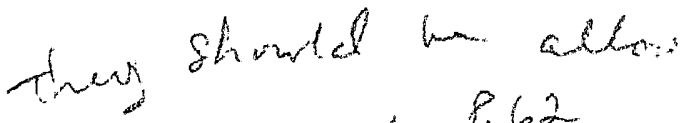

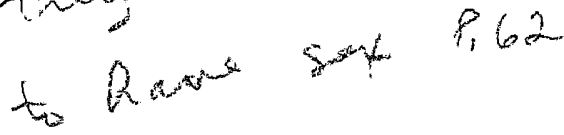


CHAPTER VI

OPERATIONALIZING THE CONCEPTS

THE LIFE SATISFACTION SCALE

Prior to 1961, the goal of research measuring the psychological we11-being of the elderly was to create an operational definition of "successful" aging. Two conceptual approaches emerged:

1) external frame of reference: emphasis was primarily on measuring the overt behavior of the individual, and utilized social criteria of success or competence (Cavan, Burgess, Havighurst, and Goldhammer, 1949; Havighurst and Albrecht, 1953). This way of measuring reflects the theoretical perspective of both Aristotle and Plato and advocates a definitive version of happiness. Activity and involvement were the measured variables. Basic to the study was the value premise that the greater the extent of social participation, and the less the individual varied from the pattern of activity that characterized him in middle age, the greater was his well-being. The implicit assumption was that only those elderly who continue to function along societally acceptable positive characteristics of middle-age could have a high level of psychological well-being in old age. A weakness of this approach was the inherent bias against those who became chronically il1, homebound, and/or had drastically reduced incomes, categories into which the vast majority of the elderly fall. 
2) internal frame of reference: emphasis was primarily on the individual's own evaluation of his/her past and present life satisfaction, and/or happiness as the measured variables (Havighurst, 1957). Using this frame of reference, the assumption is that the individual is the only proper judge of his/her well-being. This reflects the phenomenological approach to life satisfaction. Further, value judgements made by the investigator were minimized; and it was not appropriate to measure well-being in old age by the same activity and social participation standards that apply to middle-age.

In 1961, Neugarten, Havighurst, and Tobin sought to create and validate an instrument which measured successful aging. The Life Satisfaction Rating (LSR) was designed to:

1) reflect the individual's personal frame of reference

2) obtain a measure independent of other psychological and social variables.

One hundred seventy-seven men and women, ages 50-90 were interviewed. From this data emerged a fivefold construct of "Life Satisfaction" which included: zest, resolution and fortitude, congruence between desired and achieved goals, self-concept, and mood tone. An individual is regarded as being at the positive end of the continuum of well-being to the extent that he/she 1) takes pleasure from the round of activities that constitute everyday life; 2) accepts resolutely what life has been without blaming self or others for failures or disappointments; 3) feels successful in achieving major goals; 4) holds a positive image of self; and 5) maintains happy and optimistic attitudes and mood. 
The LSR proved to be statistically reliable and valid as follows: interjudge reliability, $r=.78$, Sherman-Brown coefficient of attenuation $=.87$; the correlation between the LSR and the LSR-CL (The LSR scored by clinical psychologists after interviews) $=.64$ (for ages $70+=$ .70 ; for ages $50-69=.53)$. Nevertheless, the lengthy interview, especially when administered to a large group of people, was problematic. In response, Neugarten, Havighurst, and Tobin (1961) created a short, self-report instrument called the Life Satisfaction Index-A (LSIA). It was constructed by selecting items from existing scales and by creating new items which were representative of the five previously described components of life satisfaction. It used as its validating criterion the LSR. While considerable effort went into refining the LSIA, the authors cautioned that correlations between the scales were only moderately successful, and it was recommended for use only with certain groups of persons over 65, where correlations were the highest. Wood, Wylie, and Sheafor (i969) attempted to improve the validity of the LSIA as a measure of life satisfaction. Individual item analysis suggested omission of seven of the original twenty items. The result was the Life Satisfaction Index-Z (LSIZ), a thirteen item subset of the LSIA. Statistical analysis of the LSIZ yielded the following data: test reliability of .79 using the Kuder-Richardson 20 formula which computes an average of all conceivable split halves; and construct validity of .57 of ISIZ correlated with the LSR. These results indicated that the LSIZ was a useful self-report instrument in cases where reasonable approximation of the level of psychological wel1being will suffice (Wood, et. al., 1969). 
In conclusion, the LSIZ contains the following significant components :

1) it includes the multi-dimensional aspect to the construct of Iife satisfaction

2) it reflects many of the positive aspects of thought on the subject of happiness that have filtered down through the centuries

3) the items elicit an internal frame of reference

4) the instrument allows for differentiation of life satisfaction from middle-aged activity level

5) there are adequate reliability and validity statistics for the instrument

6) It is self-reporting (free of investigator bias)

7) length of the instrument allows for presentation on a single page with adequate spacing for those with visual difficulties.

For these reasons, the LSIZ has been chosen to measure life satisfaction of the elderly population in this study (See Appendix A).

\section{DEFINITION OF SEXUAL ACTIVITY}

A sexual activity questionnaire (See Appendix B) was developed to measure sexual behaviors and non-sexual touching both with and without partners. For purposes of this study, sexuality has been broadly defined. There has been a recent emphasis on viewing sexuality as composed of several kinds of behaviors on a continuum (Podell and Perkins, 1957; Kinsey, 1953). Thus questions include a range of behaviors that extend from touching to intercourse. It was also necessary that the 
wording of the questions asked be acceptable to the age cohort being studied. As in the Kinsey research, the questions have been stated to assume that the respondent has engaged in the specific behavior. For example, rather than asking, "Have you ever sexually touched another person?" the question is phrased, "How many times have you touched another person sexually?". Kinsey's belief was that people who had not engaged in the behavior could answer "none" while those who had engaged in the behavior would be more likely to answer affirmatively. As Kinsey (1948) states,

Since it becomes apparent from the form of our question that we would not be surprised if he had such experiences, there seems less reason for denying it. (p. 53)

This phraseology sets up a receptive atmosphere for acknowlegement of having engaged in specific sexual behaviors and is believed by Kinsey to be more effective in obtaining accurate information about sexuality

Most studies that examined the sexual behavior of the elderly did so using narrow definitions of sexuality, such as Verwoerdt's (1969) exclusive focus on sexual intercourse. The expanded definition used in this study specifically includes non-genital touching, masturbation, sexual touching, penile-vaginal intercourse, orgasmic response, gender of sexual partner, and past frequency of sexual activity. The reasons for including questions on these behaviors are discussed in the following section. 


\section{DEVELOPMENT OF THE QUESTIONNAIRE}

Non-Genital Physical Contact

Research substantiates the importance of physical contact. Physical touching, holding, and rocking has been shown to be necessary to the development, health, and even survival of infants (Spitz, 1945).

The non-genital physical contact questions are an essential dimension to an expanded definition of sexuality. Few sexual behavior inventories include items such as touching, hugging, cuddling, or kissing. Current sex therapy (Masters and Johnson, 1970; Kaplan, 1974) stresses the importance of such behaviors and extensively utilizes non-genital contact between partners as part of the treatment techniques used for resolving sexual problems. Expanding the definition of sexuality also enables an examination of a wider spectrum of behaviors that could occur in either non-sexual or non-marital relationships for the aged with less risk of societal disapproval.

Non-genital forms of contact may be of increased value to aged people for several reasons. Genital contact may have ceased due to negative attitudes toward such activity for the aged or for the reasons of disease. However, non-genital contact can continue despite debilitated health of oneself or one's partner. Touching, hugging, and kissing can occur between spouses, as well as with friends and relatives.

\section{Masturbation}

Masturbation/sexual arousal with or without orgasmic release is available by self-stimulation. It is, however, contingent upon an individual's attitude toward masturbation, the physical capacity to 
stimulate one's genitals, and the privacy to do so. Data on masturbation/sexual arousal and aging individuals is somewhat scarce. Kinsey's original volumns include data for single men up to the age of 50 and married men up to the age of 60 . He found that more single than married men continue to masturbate in later years. Kinsey (1953) stated that masturbation may provide a better measure of sexual interest in heterosexual females than heterosexual activities because partner sexual activity is of ten male-initiated. Masturbation may provide the only opportunity for sexual arousal and/or orgasm for aging individuals without partners. Significantly more women, $65 \%$, than men, $29 \%$, are unmarried in this age cohort. (Kalish, 1975) Furthermore, women are less likely to be sexually involved outside of a socially sanctioned relationship, i.e., marriage (Pfeiffer and Davis, 1972). This is consistent with the previous findings of Christenson and Gagnon (1965) who found a higher frequency of masturbation among postmarital than married females. Although masturbation is sometimes seen as a substitute for interpersonal sexual relations, it is also considered to be a viable sexual option with inherent value, i.e., different from, but not less than, coitus (Barbach, 1975; Dodson, 1974). DeNicola and Peruzza (1974) determined that women in particular reported satisfaction from masturbation.

Sexua1 Touching

The two items pertaining to sexual touching are an important dimension when broadening the definition of the parameters of sexual behavior." The items on this questionnaire have been phrased to elicit a subjective definition of what the respondent considers to be sexual touching. 
Kinsey (1948, 1953) did include questions pertaining to manual stimulation of partners' genitals and breasts and found these activities to be a significant source of sexual arousal in his study.

\section{Penile-Vaginal Intercourse}

Penile-vaginal intercourse is a frequently employed category used in sexuality and aging research to measure the extent of sexual involvement. For this questionnaire, it is one of many behaviors used to measure sexual contact.

\section{Orgasm}

Orgasm is the physiological consequences of a high level of sexual arousal. The orgasmic response consists primarily of a series of invo1untary contractions of the pelvic floor muscles. The physiological capacity for orgasm remains throughout the aging years.

Orgasm is one measurement of the intensity of arousal from sexual activity; however, its significance for the aging individual is unknown.

\section{Gender of Sex Partner}

The question regarding the gender of the respondent's sexual partner was included because without specific knowledge of sexual orientation, all of the respondents would be assumed heterosexual.

\section{Past Frequency of Sexual Activity}

Research (Kinsey, 1943, 1953; Pfeiffer and Davis, 1972) found a positive correlation between levels of sexual activity in younger and later years. Masters and Johnson (1966) have said that continuation of sexual activity helps maintain sexual functioning, particularly for women. 
The importance of past patterns of behavior as it impacts on current functioning is also recognized. It seems reasonable to assume that life satisfaction may be affected by individual expectations based upon these past experiences. The focus of this study is on what norms exist for this age group. Questions were included that would provide general demographic data giving a profile of the respondent in terms of marital status, age, educational background, and other factors.

The question addressing the recency of change in residence was included because that event is often associated with heightened life stress. For the elderly, a shift in living situation might impose an even greater hardship than is incurred by a younger person, as it could signify an end to, or a movement away from, an autonomous living situation. The support system of friends and relatives could also be lost during this change, with an obvious potential decrease in general life satisfaction. It was estimated that six months would allow the individual time to resolve most of the initial turmoil associated with the move; consequently, this item was used to screen out respondents living in the residence less than six months.

The educational level of the respondent was addressed because numerous studies have shown correlations between this variable and sexual behavior: Kinsey (1948) reported individuals with less education had correspondingly negative attitudes regarding sexuality. other studies reported a gender difference: Pfeiffer and Davis (1972) found this variable to be one of the most important factors influencing the sexual behavior of men. Pfeiffer and David (1972) found a correlation 
between educational level and female sexual behavior. That is, as education increases for females, attitudes become more positive and sexual activity increases correspondingly.

Church attendance was related to female sexual interest and sexual behavior in a number of studies. Christenson and Gagnon (1965) found that church attendance has an inverse relationship to coital masturbatory activity for both the married and the unmarried. Winter (1973) found a lessening of sexual desire after menopause which he claims resulted from the linkage of sexuality to the church edict, "be fruitful and multiply".

The area of physical health has also been shown to be an important determinant of both sexual activity and life satisfaction. Pfeiffer and Davis (1972) found the health of the respondent to be an important variable in terms of sexual behavior. This was confirmed by the West, DeNicola and Peruzza (1974) study which concluded that health is an important factor for the extension of sexual behavior into old age. Kalish (1975) found health to be linked with both morale and sexual functioning, and cites diabetes, strokes, arthritis, and rheumatism and the fear of heart attacks as deterents to sexual functioning.

One frequently noted variable related to sexual functioning is the age of the individual. Kinsey (1948) indicated that $96 \%$ of men 51-55 years old and 94\% of those 56-60 in their sample, reported engaging in intercourse. Similar percentages were reported by men who were no longer married. Pfeiffer (1972) noted that with increasing age there is commonly a decrease in sexual activity and interest. Christenson and Gagnon (1972) in their study of women, found that at age 50, 
marital coitus was the chief sexual activity of $87 \%$ of women still engaging in coitus. By age 60 , the participation had dropped to $70 \%$ and by age 65 , only $50 \%$ were still experiencing coitus. In addition to a decrease in sexual activity, the factor of age was also noted by Merrit, et. al. (1975) to be related to negative sexual attitudes.

Many researchers have noted that males and females markedly differ in reported sexual behavior. Verwoerdt, et. al. (1969) and Pfeiffer and Davis (1972) found that sexual behavior is discontinued at a younger age by women than men and that women have a corresponding decrease in interest at a younger age than their male counterpart. Since women tend to marry men older than themselves, it seems reasonable to speculate that some of this may be attributable to the age of the husband. Christenson and Gagnon (1965) found that women who married men at least four year older than themselves had a lower rate of coital activity and orgasmic response. They found that $20 \%$ of women married to older men had no orgasms, whereas only $3-4 \%$ of women who were married to the same age or younger men were non-orgasmic. They concluded that the male determined the rate of coital activity.

Marital status of the aging person is significant, not only in terms of the availability of a sexual partner, but also in terms of interpersonal relationships. The elderly experience a high rate of widowhood, with $31 \%$ of women and $8 \%$ of men over the age 65 in that category. Only $1 \%$ of the widows over age 65 remarry, and many women never seek another partner after the death of their spouse. It is often difficult for these individuals to fill their sexual as well as emotional needs. Kalish (1975), West (1975), and DeNicola and Peruzza 
(1974) agreed that widowhood was an important variable in life satisfaction.

In terms of sexual behavior, both Verwoerdt, et. al. (1969) and Pfeiffer (1972) found the availability of a sexual partner to te an important determinant of sexual activity. Christenson and Gagnon (1972) found differing levels of sexual activity between married and postmarried women. Coital frequency levels were $50-66 \%$ greater for married females.

Inclusion of a question dealing with prior levels of sexual enjoyment reflects the findings of several researchers. Newman and Nichols (1960) found a strong sexual urge earlier in life tended to correlate with a continuation of similar feelings into old age. Verwoerdt, et. al. (1969) observed that with women, the enjoyment of sexual relations in younger years, rather than frequency or interest levels, seemed to be of particular importance in determining the extent of present sexual interest and frequency of intercourse. DeNicola and Peruzza (1974) also noted that sexual satisfaction prior to age 60 tended to determine satisfaction after age 60 . 
CHAPTER VII

THE PILOT STUDY

The initial draft of the questionnaire contained 26 questions. The first 8 elicited demographic data. The remaining 18 were content questions relating to a variety of sexual behaviors and attitudes toward those behaviors. This draft was utilized for a pilot study. (See Appendix B)

\section{ADMINISTRATION OF THE QUESTIONNAIRE}

Once the questionnaire was completed, it was then administered to a small sample of persons age 60 and over.as this was the cohort to be addressed in the sample for this study. The research group arbitrarily initiated contact with 11 individuals to whom the researcher was a close friend or relative in 4 cases, and was a casual friend or neighbor in the remaining 7 instances.

SUBJECTS

The 11 individuals were comprised of 3 males and 8 females ranging in age from 60 to 75. Six of those were widowed and five were married. Eight of the eleven persons contacted agreed to complete the questionnaire and six questionnaires were eventually received. In general the questionnaires were filled out, but in one case only the first page of demographic information was completed, and in another case many sexually explicit items were omitted. 


\section{INITIAL CONTACT AND SUBJECT REACTION}

All potential respondents were informed of the general nature of the study and were told that their answers would be held in strict confidence. In addition, time was allocated for "debriefing" with the older person, either after the questionnaire was completed or at another time arranged by the older person.

Two individuals flatly refused to participate, citing such feelings as their right to privacy and the impropriety of such questions.

\section{INTERVIEWER REACTION}

In nearly all cases the individuals administering the questionnaire experienced feelings of embarrassment and attributed such feelings to the highly personal nature of the questions combined with a lack of specific format for soliciting potential responses.

\section{WRITTEN RESPONSES}

One respondent indicated that the questions were "stupid" and provided no information related to sexually explicit items. In addition, the questions pertaining to oral-genital and anal contact were indicated to have been the experience of only one respondent.

\section{CONCLUSION: THE REVISED QUESTIONNAIRE}

Based on the results of the pilot study, the questions related to oral-genital and anal contact were omitted. The original rationale for including these three items was to expand the definition of 
sexuality beyond physical contact, sexual touching, coitus, and orgasm. It was also thought that anal intercourse would be an important measurement of sexual involvement of male homosexual respondents. Also, oralgenital contact is placed in a high position in sexual behavior hierarchies (Podell and Perkins, 1957) and could, therefore, be possibly considered a discriminating index of sexual involvement.

However, these items were removed from the final questionnaire because of highly negative reactions or non-response from participants in the pilot study. In addition, minor changes were made to help clarify some ambiguity that appeared to be present on a few items. The revised questionnaire contained 22 items. (See Appendix C) The first 8 elicited demographic information. The remaining 14 were content questions relating to a variety of sexual behaviors and attitudes toward those behaviors. 
CHAPTER VIII

WEIGHTING THE QUESTIONS

The following paragraphs outline the weighting of the items pertaining to the parameters of sexual behavior, items 1 through 10 (See Appendix C) and provide the basis for the assigned scores. The questions are grouped into these three categories based on a hierarchy of explicitness of sexual behaviors and the frequency with which they are likely to occur.

\section{Category I - 0 to 4 Points}

Responses to items 1 to 4 pertaining to being touched, touching another person, hugging, and kissing were scored from 1 to 4 points as follows: never $=0$, less than once a week $=1$, once a week $=2$, more than once a week $=3$, daily $=4$. Category I items are the least sexually explicit. Each of them could occur with friends, relatives, and institutional staff as well as sexual partners. These behaviors can be done with or without the intent of sexual arousal. The philosophical bias of these researchers is that such behaviors are important to well-being, whether or not sexual intent or sexual arousal is involved. In attempting to establish a continuum of point values for all the items 1 through 10 in this section, and given the likelihood that Category I behaviors were likely to occur more often than Category II and III behaviors, each item was weighted less than those in other categories. 
Category II - 0 to 8 Points

Responses to items. 5 to 7 pertaining to cuddling in bed, sexually touching another person, and being sexually touched were scored from 0 to 8 points as follows: never $=0$, less than once a week $=2$, once a week $=4$, more than once a week $=6$, daily $=8$. Category II items are more sexually explicit than Category I items. Cuddling in bed could be affectionate and not sexual, but opportunity for explicit sexual contact is likely to be more available to someone who cuddles in bed with another person. Also, the work "cuddling" as opposed to "sleeping" or "sharing a bed with" implies overt, purposeful contact. The sexual intent of "sexual touching" is implicit in the items asking about such behaviors. People who engage in Category II behaviors are likely to do so with fewer people than with Category I behaviors. This will likely result in Category II behaviors occurring less frequently, and therefore Category II behaviors are weighted more heavily than are Category I behaviors.

\section{Category III - 0 to 16 Points}

Responses to items 8 to 10 pertaining to sexual intercourse, touching oneself for sexual.pleasure, and orgasm were scored as follows: never $=0$, less than once $\mathrm{a}$ week $=4$, once $\mathrm{a}$ week $=8$, more than once a week $=12$, daily $=16$. Category III items are the most sexually explicit behaviors. They relate most directly to sexual arousal and genital contact. Intercourse, self-stimulation, and orgasm are apt to be likely to occur less of ten than the behaviors in Categories I and II. Therefore, they are: weighted more heavily in order to maintain the 
continuum of behaviors. For example, if a subject touches another person daily, the score is equivalent to having intercourse less than once a week: both items are weighted at 4 points. The limited research that does exist about sexual behavior of aged populations reveals that the frequency of intercourse declines with age. The average frequency of subjects in one study was one time per month by the age of 65 and the frequency approached zero by age 80 (Verwoerdt et. al., 1969). An analysis of the $1940^{\prime}$ s and 1950 's Kinsey data found that $27 \%$ of married and $43 \%$ of unmarried women in the sample engaged in masturbation by age 60 , but the report did not specify frequency of the activity. This same study reported that by age 60 about $18 \%$ of the women in the sample still experienced orgasm during sexual dreams, but the study did not specify the frequency (Christenson and Gagnon, 1965). Masters and Johnson's laboratory results corroborate these findings about orgasm by establishing that the physiological capacity for orgasm extends through old age.

In conclusion, because so little research has been done on the frequency of the variety of behaviors used in this study, a highly scientific analysis of the weighting is impossible. These researchers have attempted, therefore, to apply the available research and common sense to establish the weighting of scores in the three categories. 


\section{CHAPTER IX}

THE STUDY

SEARCH FOR SUBJECTS

Based on the literature review and questionnaire development, the group concluded that subjects suitable for our study would be:

-over the age of 60

-ambulatory

-cognitively oriented in person, place, and time.

In addition, a suitable sample would also be composed of:

-an equal number of males and females,

-as broad a distribution in marital status as possible,

-members from a total resident population greater than 10.

The group decided to conduct the research study at a single institution to decrease the number of extraneous variables and to simplify data collection. The State of Oregon Health Licensing Board Listings were used as a source for a list of retirement homes for the aged in Multnomah County. Contact with 33 of these homes was made, 31 initialIy by telephone and two through personal or work contact by research group members.

Of the 33 homes, $6(18 \%)$ responded "yes" to initial requests to participate in the study. The six "yes" responses were further reviewed by the group, but it was decided these retirement homes did not meet one or more of the previously stated criteria. 
Seven $(21 \%)$ responded "maybe" to initial requests. Of the seven "maybe" responses, all became "no" responses after further contact. The owners of three homes refused after they saw the questionnaire on sexual activity; they stated that the questionnaire was inappropriate and/or too personal. On second contact, one owner refused and gave no reason. The remaining three original "maybe" responses were determined by the group to be unsuitable based on the previously stated criteria. Seventeen (52\%) responded "no". The owners of nine of these homes judged their residents to be inappropriate due to psychiatric and/or health problems. The remaining eight owners had the opinion that the survey was too offensive and would upset the residents. In addition, some owners stated that the residents did not engage in sexual activity! Two (6\%) did not return the telephone call. Table III presents a detailed account of agency responses.

During the exploration of homes in the Portland area, a University staff member offered to make contact with his sister who owns a home in Seattle, Washington. The group realized that this facility did not meet all previously established criteria. However, having found no suitable and willing retirement home among the 33 homes contacted in the Portland area, and realizing the impact of time constraints, the group decided to contact the Restorative Care Center in Seattle, Washington. Use of this institution and a specific date for the study were then confirmed with the owner.*

*NOTE: Upon arrival at the Restorative Care Center on the prearranged date, the questionnaire was presented for approval to the head administrator, the assistant administrator, and the social worker. Only the 
TABLE III

SEARCH FOR SUBJECTS

I. "Yes" Responses from Agency Owners:

Agency Number: Reason Not Pursued by Research Group:

1............ Residents all female; incapacitated.

2.............Residents senile.

3................ Residents too physically. incapacitated.

4..............Agency population too small (9).

5...............Agency population too small; too many men.

6...............Agency population too small.

II. "Maybe" Responses from Agency Owners:

Agency Number: Reason Not Used for the Study:

$1 \ldots \ldots \ldots \ldots$........ nid not meet group criteria.

2............. nid not meet group criteria. (mostly female, over age 89)

3.............. nid not meet group criteria. (too physically Incapacitated)

4.............. Owner sald "no" after seeing the questionnaire.

5................... said "no" after seeing the questionnaire.

$6 \ldots \ldots \ldots \ldots$.......... changer mind stating no reason.

7............... Owner said "no" after seeing the questionnaire.

III. "No" Responses from Agency Owners:

Agency Number: Reasons Stated by Agency Owner:

1..........."Population not appropriate for the study."

2............... (no reason stated)

3............."Residents would be upset by questionnaire."

4............. "Population too small; all male; mental problems."

$5 \ldots \ldots \ldots . \ldots$ (no reason stated)

6............."Population too small and inappropriate for the study."

7............."Population to incapacitated for the study."

8............. "Sex questionnaire would be too offensive to residents."

9............"Residents would not approve of the study."

$10 . . \ldots \ldots \ldots . .$. "Not interested; find another agency."

$11 \ldots . . . \ldots . .$. "Population too small and most are confused."

12 ............"study would upset the residents; most residents inappropriate."

13............"Few residents would understand the questionnaire."

$14 \ldots . . . \ldots . .$. My ladies are too educated for your study; too religious too."

15............"Residents are too old for your study; most psychiatric patients."

$16 . . . . . . . . .$. "Most of the residents are too impaired."

$17 \ldots \ldots \ldots \ldots . . . . .1$. Residents are too confused to answer the questionnaire." 
head administrator approved use of the sexual activity questionnaire;

even she stated she would have preferred the questionnaire to be worded in a "more delicate" manner.

\section{SETTING}

The Restorative Care Center provides services for all ages in rehabilitation, extended-skilled care, intermediate care and day care. Services are available for rehabilitative patients, post-operative convalescents, short-term medical patients, long-term chronically ill persons, and out-patients.

Professional staff includes: medical director, physician, nurses, dietician, pharmecist, physical therapist, occupational therapiṣt, speech worker, and social worker. Activities include recreation, crafts, planned civic and community activities with speakers, and special programs for families. The facility offers a chapel, barber and beauty shop, hobby area, gift shop, lounges, day rooms, elevators, electronic call system, access to bus lines, meeting room, cafeterias and dining areas, inside and outside recreational area, and rooms designed for one, two or four beds. Capacity of this center is 250 patients.

This facility is licensed by the State of Washington as a Nursing Home and is certified to care for medicare, medicaid, and veterans. Nationa1ly it is accredited by the Joint Commission of Accreditation of Hospitals and is a member of American Nursing Home Association and Washington State Health Facilities Association. 


\section{SUBJECTS}

The measures of life satisfaction and sexual activity were administered to 23 of the 250 residents of the Restorative Care Center. The subjects were pre-screened by the staff social worker prior to her seeing the questionnaire. On the basis of her subjective judgement regarding their suitability for the study, she made judgements regarding willingness, interest, and ability to participate in the study. No resident was excluded on the basis of physical limitation.

23 questionnaires were returned:

-9 were unsuitable for data analysis (See Appendix D)

-14 were completed by nine females and five males and were suitable for data analysis. Table IV presents demographic characteristics of these 14 respondents.

\section{EQUIPMENT}

The instruments used were: 1) an informed consent form (See Appendix E), 2) a cover sheet that gathered demographic information, 3) the LSIZ questionnaire which measured life satisfaction, and 4) a questionnaire on sexual activity developed by this group for the research project. The latter two instruments were sequenced alternately to control for possible order effects. 
TABLE IV

DEMOGRAPHIC CHARACTERISTICS OF RESPONDENTS

Number of

Residents

LENGTH OF STAY AT RESIDENCE:

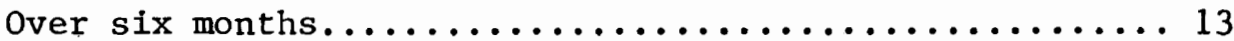

Less than $\operatorname{six}$ months......................... 1

HIGHEST LEVEL OF EDUCATION:

College graduate........................... 1

College attendance.......................... 2

High school graduate......................... 6

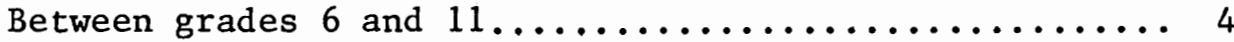

Between grades 1 and $6 \ldots \ldots \ldots \ldots \ldots \ldots \ldots \ldots \ldots$

CHURCH ATTENDANCE IN PAST 5 YEARS:

One or more times per week.................... 5

2 or 3 times per month........................ 5

3 to 12 times per year......................... 2

Never.................................... 2

SELF-EVALUATED HEALTH:

Excellent............................. 1

Good................................. 4

Fair................................. 8

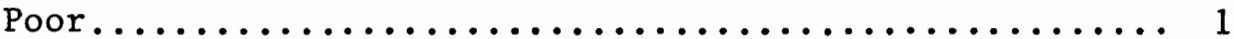

AGE :

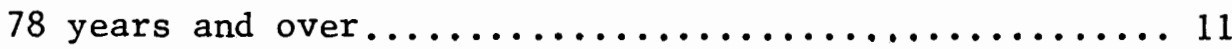

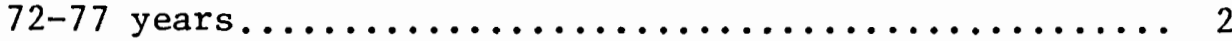

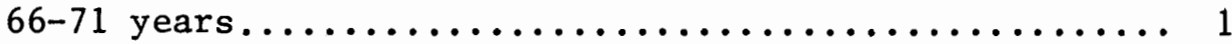

SEX:

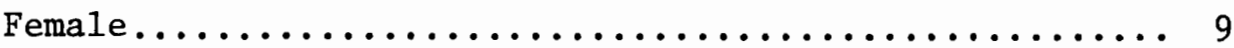

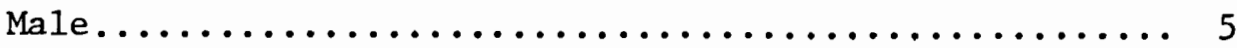

MARITAL STATUS :

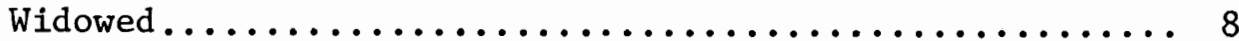

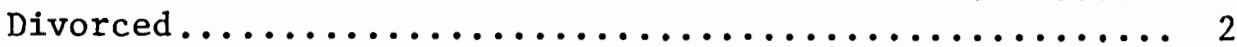

Married ................................. 4

DIVORCED, WIDOWED WITHIN PAST YEAR:

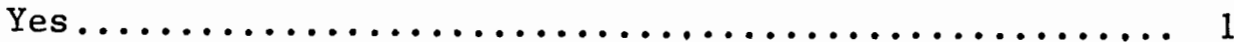

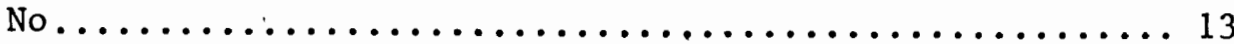


PROCEDURE

Residents were notified of the project two weeks in advance by the social worker of the agency. The morning of the research, announcements were made in the two main activity areas and dining rooms by the social worker and the three researchers. At this time, residents were reminded that the research would be conducted that afternoon and were invited to participate in the project. However, attention was focused on eliciting the participation of the residents pre-selected by the agency social worker as more appropriate for our research purposes.

The research was conducted in a conference room located in an ambulatory wing of the facility accessible from the main activities and dining areas by a long sloping ramp. Subjects in wheelchairs could not reach the room without assistance on the ramp.

The conference room contained two long tables, one small table, and several chairs. The room was carpeted, we11-1ighted, and we11ventilated.

Twelve subjects were present when the research presentation began. A short introduction was given that included identification of the researchers and purpose of the research project. Informed consent forms were distributed and were accompanied by an explanation of why they were necessary. After they were collected, instructions were given on how to mark the questionnaires.

It was explained that the answers on the questionnaires would remain confidential, and that the subjects were free to withdraw from the research at any time. Researchers were available to answer questions 
and give assistance during the time questionnaires were being administered. Subjects were told that one of the three researchers would also be available following completion of the questionnaire to discuss any personal issues that might have been raised by the content of the research. The questionnaires were distributed and it became apparent from the respondents' reactions that individual instructions were necessary. (See Appendix D) The researchers circulated around the room giving the subjects individual assistance.

Additional subjects began to arrive singly and in small groups. Many were in wheelchairs. This necessitated moving people to accommodate the wheelchairs in the already crowded room. The same procedure was followed on an individual basis as new subjects arrived.

Many of the participants required assistance in reading, and in some instances, marking the questionnaires. (See Appendix D) The research was completed in two hours. The questionnaires were placed in a closed box when completed by the respondents.

\section{RESULTS}

Scores on the life satisfaction inventory and the sexual activity questionnaire were tested for correlation ratio $(\mathrm{F}=1.67, \mathrm{df}=5,8, \mathrm{p}>.05)$ and linear correlation $(\mathrm{F}=2.45, \mathrm{df}=1,12, \mathrm{P}>.05)$. Since the correlation ratio and the linear correlation were not significant, Eta was used to investigate the relationship between life satisfaction and sexual activity. Results showed that $\eta=.52$, and was not significant as found by the $F$ test of curvilinearity $(F=1.39, d f=4,8, p>05)$. A scatter-plot of the data revealed scores polarized at the ends of the sexual behavior 
continuum. Scores on both life satisfaction inventory, and the sexual activity questionnaire, were transformed by multiplying by 100 , dividing in half at the median and analyzed by means of $2 \times 2 \pi^{2}$. Results showed $X^{2}=.16, \mathrm{df}=1, \mathrm{p}>.05$.

Because polarized scores might have reflected differing responses, a post hoc analysis of questions $1-6$ on the sexual activity questionnaire and the life satisfaction inventory was performed. Results showed that $F$ tests for correlation ratio $(F=1.43, d f=5,8)$ and for linear correlation $(F=2.74, d f=1,11)$ were not significant. Data were then analyzed by means of Eta, $\eta=.69$ which also was not significant $(F=1.08, \mathrm{df}=4,8, \mathrm{p}>.05)$.

Using the Spearman Rank-Order Correlation Coefficient, sexual activity scores were compared separately with church attendance, and educational level of achievement. For sexual activity and church attendance, $P=1.5, p>.05$, for sexual activity and educational level of subjects $p=.12, p>05$.

The results of the analyses of data showed no significant relationships between life satisfaction and sexual activity, and no significant relationships between life satisfaction and educational level, health, or church attendance. The results also indicated the lack of significant relationship between sexual activity and educational level or church attendance. 
CHAPTER X

\section{DISCUSSION}

The data from this research study do not support the hypothesis of a positive relationship between life satisfaction and sexual activity among the institutionalized aged. The researchers believe that results were biased due to sample, instrument, and methodology problems.

Due to the previously outlined difficulties in securing a sample congruent with the established criteria, the group elected to study an available sample that was more limited in cognitive and physical characteristics than established by previous criteria. The research was conducted in a nursing home rather than in a home for the aged which resulted in unanticipated difficulties concerning the respondents' reading, understanding, and answering the questionnaires. These difficulties are detailed in the appendix (See Appendix D).

The methodological problems concern method of presentation of the introductory instructions, non-standardized assistance for questionnaire completion and inappropriate control for privacy. Contrary to the researchers' expectations, most of the subjects did not adequately comprehend the instructions that were presented by large group format. The researchers then chose to assist the subjects on a one-to-one basis and adapted the instructions according to the individual's needs. Consequently, instructions and assistance in completing the questionnaire were non-standardized. Additionally, the research group did not provide 
a setting with adequate privacy to insure confidentiality and uninfluenced responses.

Results from the pilot study, refusals by agencies to participate after seeing the questionnaire, and difficulty in questionnaire completion point to several problems. with the instruments. Many of the subjects directly expressed difficulty interpreting the items on both questionnaires. Some pilot study participants, agencies, and subjects objected to the sexual content of the sexual behavior inventory questions. Inexperience of the researchers in dealing with this age cohort and in designing the sexual behavior questionnaire many only in part explain these difficulties. Negative attitudes toward sexuality must also be considered as a contributing factor.

The researchers conducted post hoc analysis of some of the data in an attempt to determine if correlations previously established in the literature were upheld in this study. The literature suggested specific relationships between the following pairs of variables: sexual activity and church attendance, sexual activity and educational level, and life satisfaction and health. This study did not yield such correlations. While the literature did not discuss life satisfaction and church attendance, or life satisfaction and educational level, the researchers attempted to see if this study revealed such correlations. No significant relationships were found.

The researchers believe that despite the lack of statistical results, valuable information regarding research in the area of sexuality has been acquired. A pervasive theme throughout the development and implementation of this study was the discomfort about the subject 
matter of sexuality. Discomfort was documented in the review of the literature and observed in the reactions of the agency directors, the reactions of subjects of the pilot study and final study, and the discussions of the research group. The negative societal attitudes towards sexual expression of older people, as documented in the review of the literature may contribute to the restrictive institutional practices and policies concerning sexual access and activities of residents. The resistance of agencies to participate in this study involving sexuality was highlighted by the refusal of one agency, despite the considerable efforts of the group to involve and prepare the agency. Furthermore, even several of the staff in the agency that participated in the study did not want to do so because of the sexual subject matter. In the pilot study, refusals to participate and failures to return the questionnaire were also indicative of discomfort in responding to a sexuality questionnaire. Some pilot study subjects voiced strong disapproval of the sexual content of the questions. In the final study some subjects expressed similar reactions. Group members also acknowledged occasional feelings of personal discomfort with the topic of sexuality, especially when administering the sexual activity questionnaire. 
CHAPTER XI

\section{CONCLUSION}

The hypothesis of this study was not supported. The data are inconclusive due to the difficulties previously described. The current task of the researchers is to use the problems encountered during the research to suggest several areas for revision which may lead to more conclusive results. The researchers recommend revisions in the areas of groundwork, sample, methodology, and instrument design.

The researchers' lack of thorough familiarity with this age cohort contributed to difficulty in questionnaire design and administration. Preliminary first-hand experiences with older persons and additional, on-going consultations with experts in the field of sexuality and aging, in addition to the literature review actually conducted, would more thoroughly prepare the researchers for the study. The researchers consider the use of an appropriate home for the aged to be crucial to the research effort. With a heightened sensitivity to the concerns of the elderly regarding sexuality, and with a greater facility in communicating. clearly and concisely with the elderly, the researchers may have encountered greater success in contracting with an appropriate agency. Once the initial agency contact is made, further groundwork for successful research could be laid through extensive communication and cooperation between researchers and agency personnel with the goal of creating 
an appropriate instrument by which to measure sexual activity of the sample. The researchers and agency personnel need to work hand-in-hand to educate each other to the needs of the sample and the study. Sexuality education for agency staff is recommended as a part of this process in order to reduce some of the expected resistance. Experts could be used to provide sex education necessary to prepare agency staff. Through the model of mutual participation and education, the researchers should be able to create a research design and method of administration more suitable than those used in the present study.

The research group, in retrospect, realized the need for a wel1conceived and administered pilot study. The pilot study would have provided the researchers additional information about appropriate methodology and the age cohort in question. For both the pilot and the final studies, the researchers recommend ample time allocation for visiting the facility and planning the questionnaire-administration phases. Planning should include steps to ensure an adequate test-taking environment with the provision for privacy and ample time for questionnaire completion. In addition, the researchers recommend that the sexual behavior inventory questionnaire be administered by a one-to-one interview format.

Although subjects voiced difficulty in understanding the LSIZ, reliability and validity for this instrument have been established. The researchers recommend retaining the LSIZ but modifying some aspects of the sexual behavior inventory. "In response to complaints from some of the subjects, the following modifications of the sexual behavior inventory are suggested. The introductory description of the questions 
as "sexual behaviors" should be removed, clarifying that touching can occur between the subject and friends, family, spouses, and staff. The word "pleasurably" should be removed from the touching questions. Examples of touching (such as hand-holding, an arm around another person, and a pat on the back) should be given. Incorporating other sexual behavior inventories used with this age cohort may be helpful in improving the present inventory.

In conclusion, the researchers believe that many of the difficulties encountered during the study stem from overall societal resistance, to dealing with sexuality especially with the age cohort studied. It is anticipated that any research in the area of sexuality and the aged would encounter attitudinal obstacles. The suggestions enumerated represent an attempt, garnered from the researchers' experience in this study, to deal more sensitively and effectively with these problems. We maintain that further research in the field of aging and sexuality is needed.

It is desirable for social workers to consider all aspects of individuals' needs and issues concerning sexuality. Results from this study indicate the large barriers that exist in addressing these needs of older persons. Without first understanding both personal and societal resistance to considering sexual issues, a social worker cannot intervene effectively: Because social workers will be among the key professionals in contact with the ever-growing members of older people, it is imperative that these barriers be removed so that those who do achieve greater life satisfaction by realizing their sexuality will be enabled to do so. 


\section{BIBLIOGRAPHY}

Adams, David L. 1969. "Analysis of Life Satisfaction Index", Journal of Gerontology, XXIV, 470-474.

Aldrich, C.K. 1964. "Personality Factors and Mortality in the Relocation of the Aged", The Gerontologist, IV, 92-93.

Aldrich, C.K. and E. Mendkoff. 1963. "Relocation of the Aged and Disabled: A Mortality Study", Journal of the American Geriatrics Society, II, 185-194.

Amulree, B. 1954. "Sex in the Elderly", Practitioner, CLXXII, 431.

Anderson, F. 1976. Practical Management of the Elderly. Oxford: Blackwe11 Scientific Publications, 351.

Anderson, Nancy N. 1967. "Effects of Institutionalization on SelfEsteem", Journal of Gerontology, XXII, 313-317.

Barbach, Lonnie Garfield. 1975. For Yourself: A Guide to Sexual Fulfillment. New York: Doubleday.

Be1lak, Leopold, M.D. and Toksoz Karasu, M.D. 1976. Geriatric Psychiatry. New York: Grune and Stratton.

Bennett, Ruth and Lucille Nahemow. 1965. "Institutional Totality and Criteria of Social Adjustment in Residences for the Aged", Journal of Social Issues, XXI, 44-78:

Berezin, Martin A. 1969. "Sex and 01d Age: A Review of the Literature", Journal of Geriatric Psychiatry, II, 131-149.

Birren, J.E. 1964. The Psychology of Aging. Inglewood Cliffs, New Jersey: Prentice-Hall.

Blackman, Donald K. 1976. "Increasing Participation in Social Interaction of Institutionalized Elderly", The Gerontologist, XVI, 69-76.

Blenkner, M. 1967. "Environmental Change and the Aging Individual", The Gerontologist, VII, 101-105.

Bloom, Kenneth. 1961. "Age and Self-Concept", American Journal of Psychiatry, CXVIII, 534-538.

Boston Womens' Health Book Collective. 1976. Our Bodies, Ourselves. New York: Simon and Schuster. 
Bourestom, Norman and Sandra Tars. 1974. "Alterations in Life Patterns Following Nursing Home Relocation", The Gerontologist, XIV, 506-510.

Brink, S.L., D. Capri, V. DeNeeve, C. Janakes, and Oliveira. 1978. "Senile Confusion: Limitations of Assessment by the Face-Hand Test, Mental Status Questionnaire, and Staff Ratings", Journal of the American Geriatrics Society, XXVI, 380-382.

Bultena, Gordon L. and Robert Oyler. 1971. "Effects of Health on Disengagement and Morale", Aging and Human Development, II, 142-148.

Burnside, Irene Mortenson, ed. 1976. "Sexuality and the Aged", Nursing and the Aged, New York: McGraw-Hill, 452-464.

Busse, E.W., R.H. Barnes, A.J. Silverman, G. Shy, M. Thaler, and L.L. Frost. 1954. "Studies of the Process of Aging...Factors that Influence the Psyche of Elderly Persons", American Journal of Psychiatry, CX, 897-903.

Butler, Robert N., M.D. 1975. Why Survive. New York: Harper and Row Publishers, Inc.

Butler, Robert N. and Myrna I. Lewis. 1976. Sex after Sixty. New York: Harper and Row Publishers, Inc.

Cameron, Paul. 1976. "Masculinity/Femininity of the Generations: As Self-Reported and as Stereotypically Appraised", International Journal of Aging and Human Development, VII, 143-151.

Cavan, R.S., E.W. Burgesi, R.J. Havighurst, and H. Goldhamer. 1949. Personal Adjustment in 0ld Age. Chicago: Science Research Associates.

Christenson, Cornelia V. and Alan Blain Johnson. 1973. "Sexual Patterns in a Group of Never-Married Women", Journal of Geriatric Psychiatry, VI, 80-98.

Christenson, Cornelia V. and J.H. Gagnon. 1965. "Sexual Behavior in a Group of Older Women", Journal of Gerontology, XX, 351-356.

Cleveland, Martha. 1976. "Sex in Marriage: At 40 and Beyond", The Family Coordinator, XXV, 233-240.

Comfort, Alex. 1974. "Sexuality and 01d Age", Journal of the American Geriatrics Society, XXII, 440-442.

Costello, J.P. 1975. "Sex, Intimacy and Aging", American Journal of Aging, LXXV, 1330-1332. 
Costello, J.P. and G.M. Tanaka. 1961. "Mortality and Morbidity in Long-Term Institutional Care of the Aged", Journal of the American Geriatrics Society, VIX, 959-964.

Dean, Stanley. 1966. "Sin and Senior Citizens", Journal of the American Geriatrics Society, XIV, 935-938.

Dean, Stanley. 1974. "Geriatric Sexuality: Normal, Needed, and Neglected", Geriatrics, 134-137.

DeNicola, Pietro and Marino Perussa. 1974. "Sex in the Aged", Journal of the American Geriatrics Society, XXII, 380-382.

DeWever, Margaret K. 1977. "Nursing Home Patients Perception of Nurses' Effective Touching", The Journal of Psychology, XCVI, 163-171.

Dickerson, Peter. 1974. The Fires of Autumn. New York: Drake Publishers, Inc.

Dodson, Betty. 1974. Liberating Masturbation. New York: Betty Dodson.

Donahue, Wilma, Dorothy Coons, and Leonard E. Gotterman. 1969. 슴 Therapeutic Milieu for Geriatric Patients. Ann Arbor: University of Michigan.

Donahue, Wilma, W. Hunter, and Dorothy Coons. 1953. "A Study of the Socialization of 01d People", Geriatrics, VIII, 656-666.

Downie, N.M. and R.W. Heath. 1974. Basic Statistical Methods. New York: Harper and Row Publishers, Inc.

Epstein, Leon J. 1968. "Institutional Planning", in Aging in Modern Society. Edited by A. Simon and L. Epstein. Washington, D.C.: American Psychiatric Association.

Erickson, Erik. 1963. Childhood and Society. New York: W.W. Norton and Company.

Feigenbaum, E.M. 1967. "Sexual Attitudes in the Elderly", Geriatrics, XXII, 42.

Feigenbaum, E.M., M.F. Lowentah1, and M.L. Trier. 1967. "Aged are Confused and Hungry for Sex Information", Geriatric Focus, V, 2.

Felstein, Ivor. 1970. Sex in Later Life. Baltimore: Penguin.

Finkle, A.L. 1971. "Sexual Function During Advancing Age", in Clinical Geriatrics. Edited by I. Rossman. Philadelphia: J.B. Lippincott Co., 473 . 
Finkle, A.L. 1976. "Sexual Aspects of Aging", in Geriatric Psychiatry. Edited by L. Bellak and T.B. Karasu. New York: Grune and Stratton, 63.

Finkle, A.L. and P.S. Finkle. 1977. "How Counseling May Solve Sexual Problems in Aging Men", Geriatrics, XXXII, 84.

Finkle, Alex L. 1978. "Genitourinary Disorders of old People: Therapeutic Considerations Including Counseling for Sexual Dysfunction", Journal of the American Geriatrics Society, XXVI, 453-458.

Freeman, Y.T. 1961. "Sexual Capacities in the Aging Male", Geriatrics, XVI, 37.

Glover, B.H. 1975. "Family Practice and Problems of Aging", Postgraduate Medicine, $57(8)$, 165-168.

Goffman, E. 1960. "Characteristics of Total Institutions", in Identity and Anxiety: Survival of the Person in Mass Society. Edited by M.R. Stein, J. Vidich, and M. White. Glencoe: Free Press, 449-479.

Golde, P. and N. Kogan. 1959. "A Sentence Completion Procedure for Assessing Attitudes Toward 01d People", Journal of Gerontology, XIV, 355-360.

Goldfarb, A.I. 1959. "Depression, Brain Damage and Cronic Illness of the Aged; Psychiatric Diagnosis and Treatment", Journal of Chronic Illness, IX, 220-223.

Goldfarb, A.I. 1964. "The Evaluation of Geriatric Patients Following Treatment", in The Evaluation of Psychological Treatment. Edited by P.H. Hock and J. Zubin. New York: Grune and Stratton.

Goldfarb, A.I., S.P. Shahinian, and H. Turner. 1966. "Death Rates of Relocated Nursing Home Residents". Paper presented at the 17 th annual meeting of Gerontological Society, New York.

Goldfarb, Alvin. 1968. "Social Planning", in Aging in Modern Society. Edited by A. Simon and L. Epstein. Washington, D.C.: American Psychiatric Association.

Green, M.A. and M. Fink. 1954. "Standardization of the Face-Hand Test", Neurology, IV, 211.

Gubrium, Janer F. 1973. The Myth of the Golden Years: A SocioEnvironmental Theory of Aging. Springfield, Illinois: Charles C. Thomas, Publishers.

Halbfinger, Joseph D. 1976. "The Aged in Institutions", Ph.D. Dissertation, Case Western Reserve University. 
Harlow, H.F. and M.K. Harlow. 1969. "Effects of Various MotherInfant Relationships on Rhesus Monkey Behaviors", in Determinants of Infant Behavior IV. Edited by B.M. Foss. London: Methun.

Havighurst, R. 1957. "The Social Competence of Middle Aged People", Genetic Psychology Monographs. LVI, 297-375.

Havighurst, R.J. and R. Albrecht. 1953. Older People. New York: Longmans Green.

Havighurst, Robert J., Bernice L. Neugarten, and Sheldon S. Tobin. 1968. "Disengagement and Patterns of Aging", in Middle Age and Aging. Chicago: University of Chicago Press.

Jasnau, Kenneth F. 1967. "Individualized vs. Mass Transfer of Nonpsychotic Geriatric Patients from Mental Hospitals to Nursing Homes, with Special Reference to the Death Rate", Journal of the American Geriatrics Society, XV, 280-284.

Jones, H. Mumford. 1953. The Pursuit of Happiness. Cambridge: Harvard University Press.

Kahana, B.L. 1976. "Social and Psychological Aspects of Sexual Behavior Among the Aged", in Aging and Reproductive Physiology. Edited by E.S.E. Hafex. Ann Arbor, Michigan: Ann Arbor Science, 89.

Kahn, R.L., M. Pollack, and A.I. Goldfarb. 1961. "Factors Related to Individual Differences in Mental Status of Institutionalized Aged", in Psychopathology of Aging. Edited by P.H. Hoch and J. Zubin. New York: Grune and Stratton, 104-113.

Kalish, Richard A. 1975. Late Adulthood: Perspectives on Human Development. Monterey: Brooks/Cole Publishing Co., Inc.

Kaplan, H.B. and Alex D. Pokorny. 1969. "Self-Derogation and Psychosocial Deviance", Journal of Nervous and Mental Disease, CXLIX, 421-434.

Kaplan, Helen Singer. 1974. The New Sex Therapy. New York: Quadrangle.

Kas1, Stanislav V. 1972. "Physical and Mental Health Effects of Involuntary Relocation and Institutionalization of the Elderly-A Review", American Journal of Public Health, LXII, 377-383.

Katts, Gilbert R. and Keith E. Davis. 1971. "Effects of Volunteer Bias in Studies of Sexual Behavior and Attitudes", The Journal of Sex Research, VII, 6-34.

Killian, Eldon C. 1970. "The Effect of Geriatric Transfers on Mortality Rates", Social Work, XV, 19-26. 
Kinsey, A.C., W.B. Pomeroy, and C.E. Martin. 1948. Sexual Behavior in the Human Male. Philadelphia: W.B. Saunders Company.

Kinsey, Alfred C., Wardell B. Pomeroy, Clyde E. Martin and Paul H. Gebhard. 1953. Sexual Behavior in the Human Female. Philadelphia: W.B. Saunders Company.

Kraus, A.S., R.A. Spasoff, E.J. Beattie, E.W. Holden, J.S. Lawson, M. Rodenburg., and E.M. Woodcock. 1976. "Elderly Applicants to Long-Term Care Institutions: I. Their Characteristics, Health Problems and State of Mind", Journal of the American Geriatrics Society, IV, 117-125.

Kretch, David and Richard Crutchfield. 1966. Elements of Psychology. New York: Alfred A. Knopf Company.

Kuppe, G., H. Metzger and H. Ludwig. 1976. "Aging and Structural Changes in Female Reproductive Tract", in Aging and Reproductive Physiology. Edited by E.S.E. Hafez, Ann Arbor: Ann Arbor Science, 21 .

Larson, Reed. 1978. "Thirty Years of Research on the Subjective We11Being of older Americans", Journal of Gerontology, XXXIII, 109125.

LaTorre, Ronald and Karen Kear. 1977. "Attitudes Toward Sex in the Aged", Archives of Sexual Behavior, VI, 203-212.

Lawton, M. and S. Yaffe. 1967. "Mortality, Morbidity and Voluntary Change in Residence". Paper presented at the Meeting of the American Psychological Association, Washington.

X Lieberman, M.A., V.N. Prock, and S.S. Tobin. 1968. "Psychological Effects of Institutionalization", Journal of Gerontology, XXIII, 343-353.

Lieberman, Morton. 1961. "Relationship of Mortality Rates to Entrance to a Home for the Aged", Geriatrics, XVI, 515-519.

Lieberman, Morton A. 1969. "Institutionalization of the Aged: Effects of Behavior", Journal of Gerontology, XXIV, 330-340.

Lieberman, Morton and M. Lakin. 1977. "On Becoming an Aged Institutionalized Individual", in The Evaluation of Psychological Treatment. Edited by W. Donahue, C. Tibbitts, and R. Williams. New York: Atherton Press, 475-503.

Lohmann, Nancy. 1977. "Correlations of Life Satisfaction, Morale and Adjustment Measures", Journal of Gerontology, XXXII, 73-75.

Long, Irene. 1976. "Human Sexuality and Aging", Social Casework, LVII, $237-244$. 
MacFarland, R.A. 1968. "The Sensory and Perceptual Processes in Aing", in K.W. Schaie (ed.) Theory and Methods of Research on Aging. Morgantown, West Virginia: West Virginia University Library.

Marcus, I. and J. Francis. 1975. Masturbation from Infancy to Senescence. New York: International University Press, Inc.

Masters, William and Virginia Johnson. 1970. Human Sexual Inadequacy. Boston: Little, Brown, and Company.

Masters, William H. and Virginia E. Johnson. 1966. Human Sexua1 Response. Boston: Little, Brown, and Company.

McKinley, Hedi and Belle Drew. 1977. "The Nursing Home: Death of Sexual Expression", Health and Social Work, II, 180-187.

McNemar, Quinn. 1949. Psychological Statistics. New York: John Wiley and Sons, Inc. Chapter 13, pp. 231-235 and pp. 311-313.

Mercer, Susan 0. 1978. "Helplessness and Hopelessness in the Institutionalized Aged: A Field Experiment on the Impact of Increased Control and Choice", D.S.W. dissertation, University of Utah.

Merritt, C.G., J.E. Gersh, and L.A. LoSciento. 1975. "Age and Perceived Effects of Erotica-Pornography: A National Sample Study", Archives of Sexua1 Behavior, IV, 605-621.

Miller, D. and M.A. Lieberman. 1965. "The Relationship of Affect State Adaptive Reactions to Stress", Journal of Gerontology, XX, 492-497.

Neugarten, Bernice. 1965. "Age, Norms, Age Constraints, and Adult Socialization", American Journal of Sociology, LXX, 70-73.

Neugartè, Bernice, R.J. Havighurst, and Sheldon Tobin. 1961. "Measurement of Life Satisfaction", Journal of Gerontology, XXVI, 134-143.

Newman, G." and C.R. Nichols. 1960. "Sexual Activities and Attitudes in Older Persons", Journal of the American Medical Association, CLXXIII, 33-35.

Nunnally, Jum C. Jr. 1970. Introduction to Psychological Measurement. New York: McGraw-Hill Book Company. Chapter 5.

Oberleder, Muriel. 1976. "Managing Problem Behaviors of Elderly Patients", Hospital and Community Psychiatry, XXVII, 325-330.

Page, Jane. 1977. The Other Awkward Age. Berkeley: Ten Speed Press. 
Palmore, Erdman. 1970. "Total Chance of Institutionalization Among the Aged", Gerontologist, XXVI, 504-516.

Palmore, Erdman (ed.). 1974. Normal Aging II: Reports from the Duke Longitudinal Study: 1970-1973. Durham, N.C.: Duke University Press.

Peterson, James and Barbara Payne. 1975. "Love in the Later Years", The Emotional, Physical, Sexual and Social Potential of the Elderly. New York: Associated Press.

Pfeiffer, Eric. 1969. "Sexual Behavior in 01d Age", Behavior and Adaptation in Late Life. Boston: Little, Brown, and Company.

Pfeiffer, Eric. 1974. "Sexuality in the Aging Individual", American Geriatrics Society, XXII, 481-484.

Pfeiffer, Eric, Adriaan Verwoerdt, H.S. Wang. 1968. "Sexual Behavior in Aged Men and Women", The Archives of General Psychiatry, XIX, 753-758.

Pfeiffer, Eric, Adriaan Verwoerdt, and Glenn C. Davis. 1972. "Sexual Behavior in Middle Life", American Journal of Psychiatry, 12621267.

Pfeiffer, Eric and Glenn C. Davis. 1972. "Determinants of Sexual Behavior in Middle and Old Age", Journal of the American Geriatrics Society, $\mathrm{XX}, 151-158$.

Pincus, Allen. 1968. "The Definition and Measurement of the Institutional Environment in Homes for the Aged", Gerontologist, VIII, 207-210.

Plutchik, R., H. Conte, and M. Lieberman. 1971. "Development of a Scale (GEIS) for Assessment of Cognitive and Perceptual Functioning in Geriatric Patients", Journal of the American Geriatrics Society, XIX, 614 .

Plutchik, R., H. Conte, M. Lieberman, M. Bakur, J. Grossman, and N. Lehrman. 1970. "Reliability and Validity of a Scale for Assessing the Functioning of Geriatric", Journal of the American Geriatrics Society, XVIII, 491.

Pode11, Lawrence and John Perkins. 1957. "A Guttman Scale for Sexual Experience - A Methodological Note", Journal of Abnormal and Social Psychology, LIV, 420-422.

Pollack, M., E. Karp, R.L. Kahn, and A.I. Goldfarb. 1967. "Perception of Self in Institutionalized Aged Subjects. Response Patterns to Mirror Reflection", Journal of Gerontology, XVII, 405-408. 
Puner, Morton. 1974. "Will You Still Love Me?", Human Behavior, IV, 42-48.

Rahe, R.H. 1964. "Social Stress and Illness Onset", Journal of Psychosomatic Research, VIII, 35-44.

Rahe, R.H. 1969. "Life Crisis and Health Change", in Psychotropic Drug Responses, Advances in Prediction. Springfield, IL: Charles Thomas.

Reingold, J. and Rose Dobrof. 1965. "Organization Theory and Homes for the Aged", The Gerontologist, V, 88-95.

Riegal, K.F. and K.M. Riegal. 1960. "A Study on Changes of Attitudes and Interest During Later Years of Life", Vita Human, III, 173.

Riley, M.W., A. Foner and Associates. 1968. Aging and Sexuality, An Inventory of Research Findings. New York, New York: Russell Sage.

Rossman, I. (ed.). 1971. Clinical Geriatrics. Philadelphia: J.B. Lippincott.

Rowland, Kay F. and Stephen N. Haynes. 1978. "A Sexua1 Enhancement Program for Elderly Couples", Journal of Sex and Marital Therapy, XIV, 91-112.

Rubin, Isadore. 1966. Sexual Life After Sixty. New York: Basic Books, Inc.

Rubin, Isadore. 1976. "The Sexless Older Years: A Socially Harmful Stereotype", in Growing 01d in America. New Brunswick: Transaction Books.

Sanders, Faye. 1976. "Aspects of Sexual Counseling with the Aged", Social Casework, October, 504-510.

Shanas, E. 1962. The Health of Older People. Cambridge, Massachusetts: Harvard University Press.

Silverstone, B. and L. Wynter. 1975. "The Effects of Introducing a Heterosexual Living Space", The Gerontologist, XV, 83-87.

Skinner, B.F. 1953. Science and Human Behavior. New York: MacMillan Company.

Snyder, Eldon and Elmer Spreitzer. 1976. "Attitudes of the Aged Toward Nontraditional Sexual Behavior", Archives of Sexual Behavior, $\mathrm{V}, 249-253$.

Spinazzola, Angelo." 1975. "Sexual Patterns in the Process of Aging", Health Education, VI, 11-14. 
Spitz, R.A. 1945. "Hospitalism", The Psychoanalytic Study of the Child, I, 53-74.

Stahmann, Robert F., Ph.D., ed. 1977. "The Climacteric Years in the Man, Woman, and Family", in Klemer's Counseling in Marital and Sexual Problems. Baltimore: Williams and Wilkens, Co., 283291.

Stanford, Dennyse. 1977. "All About Sex...After Middle Age", American Journal of Nursing, LXXVII, 608-611.

Stephens, J. 1974. "Romance in S.R.O.: Relationship of Elderly Men and Women in a Slum Hotel", The Gerontologist, XIV, 279-282.

Stevens, Joyce. 1976. "Romance in the S.R.O.", in Growing Old in America. Edited by Beth Hess, New Brunswick: Transaction Books.

Stokes, W.R. 1951. "Sexual Capacities in the Aging Male", Geriatrics, VI, 304.

Strickler, M. 1975. "Crisis Intervention in the Climacteric Man", Social Casework, LVI, 85-89.

Sviland, Mary A. 1975. "Helping Elderly Couples Become Sexually Liberated: Psycho-social Issues", Counseling Psychologist, V, $67-72$.

Tobin, Sheldon. 1976. Last Home for the Aged. San Francisco: JosseyBass.

To11, Lillian and Joan and Kenneth Israel. 1977. Looking Ahead, A Woman's Guide to Problems and Joys of Growing O1der, New Jersey: Prentice-Hall.

Townsend, P. 1962. The Last Refuge - A Survey of Residential Institutions and Homes for the Aged in England and Wales. London: Routledge \& Kegan Paul.

Verwoerdt, Adriaan, Eric Pfeiffer, and H.S. Wang. 1969. "Sexual Behavior in Senescence", Geriatrics, XXIV, 137-154.

Wasow, Mona and Martin B. Loeb. 1977. "The Aged", in The Sexually Oppressed. Edited by Harney L. and Jean S. Gochros. New York: Associated Press.

Weckler, R. and Peg Grey. 1968. Sex and the Senior Citizen. New York: Frederick Fall, Inc.

Weg, R.B. 1975. "Sexual Inadequacy in the Elderly", in The Physiology and Pathology of Human Aging. Edited by R. Goldman and M. Rockstein, New York: Academic Press Inc., 203. 
Weidinger, Paula. 1977. Menstruation and Menopause. New York: Delta.

West, Norman D. 1975. "Sex in Geriatrics: Myth or Miracle?", Journal of the American Geriatrics Society, XXIII, 551-552.

Winter, Ruth. 1973. Ageless Aging. New York: Crown Publishers.

Wiseman, Jacqueline P. 1976. The Social Psychology of Sex. New York: Harper and Row, 228-233.

Wish, Carol W. 1977. "The Relationship of Sex Role Typing to Life Satisfaction in 01der Persons", Dissertation Abstracts International, XXXVII, 5820-5821.

Wood, Vivian, Mary L. Wylie and Bradford Sheafor. 1969. "An Analysis' of a Short Self-Report Measure of Life Satisfaction: Correlation with Rater Judgements", Journal of Gerontology, XXIV, 465-469. 


\section{APPENDIX A}

\section{LSIZ QUESTIONNAIRE}

HERE ARE SOME STATEMENTS ABOUT LIFE IN GENERAL THAT PEOPLE FEEL DIFFERENTLY ABOUT. hOULD YOU READ EACH STATEMENT ON THE LIST, AND IF YOU AGREE WITH IT, PUT A CHECK NARK IN THE SPACE UNDER "AGREE". IF YOU DO NOT AGREE WITH A STATEMENT, PUT A CHECK MARK IN THE SPACE UNDER "DISAGREE". IF YOU ARE NOT SURE ONE hAY OR THE OTHER, PUT A CHECK MARK IN THE SPACE UNDER "?". PLEASE BE SURE TO MAKE A CHECK MARK FOR EVERY STATERENT ON THE LIST.

\begin{tabular}{|c|c|c|c|c|}
\hline & & AGREE & DISAGREE & ? \\
\hline A. & $\begin{array}{l}\text { As I grow older, things seem better than } \\
\text { I thought they would be. }\end{array}$ & & & \\
\hline & $\begin{array}{l}\text { I have gotten more of the breaks in life } \\
\text { than most of the people I know. }\end{array}$ & & & \\
\hline c. & This is the dreariest time of my life. & & & \\
\hline D: & I am just as happy as when I was younger. & & & \\
\hline E. & These are the best years of my 1 ife. & & & \\
\hline & $\begin{array}{l}\text { Most of the things I do are boring or } \\
\text { monotonous. }\end{array}$ & & & \\
\hline & $\begin{array}{l}\text { The things I do are as interesting to me } \\
\text { as they ever were. }\end{array}$ & & & \\
\hline & $\begin{array}{l}\text { As I look back on my life, I am fairly. } \\
\text { well satlsfied. }\end{array}$ & . & & \\
\hline & $\begin{array}{l}\text { I have made plans for things I' } 11 \text { be } \\
\text { doing a month or a year from now. }\end{array}$ & & & \\
\hline & $\begin{array}{l}\text { When I think back over my } 11 \text { fe, I didn't } \\
\text { get most of the important things I wanted. }\end{array}$ & & & \\
\hline & $\begin{array}{l}\text { Compared to other people, I get down in } \\
\text { the dumps too often. }\end{array}$ & & & \\
\hline & $\begin{array}{l}\text { I've gotten pretty much what I expected } \\
\text { out of life. }\end{array}$ & & & \\
\hline & $\begin{array}{l}\text { In spite of what people say, the lot of } \\
\text { the average man is getting worse, not } \\
\text { better. }\end{array}$ & & & \\
\hline
\end{tabular}


APPENDIX B

PRE-TEST SEXUALITY QUESTIONNAIRE

DURING THE LAST FOUR WEEKS:

HOW OFTEN HAVE YOU BEEN PLEASUREABLY TOUCHED BY ANOTHER PERSON?

never less than once a week more than daily once a week once a week

HOW OFTEN HAVE YOU TOUCHED ANOTHER PERSON FOR PLEASURE?

never less than once a week more than daily once a week once a week

HOW MANY TIMES HAVE YOU AND ANOTHER PERSON HUGGED?

never less than once a week more than daily once a week once a week

HOW MANY TIMES HAVE YOU AND ANOTHER PERSON KISSED?

never less than
once a week $\quad$ once a week $\begin{aligned} & \text { more than } \\ & \text { once a week }\end{aligned} \quad$ daily

HOW MANY TIMES HAVE YOU AND ANOTHER PERSON CUDDLED IN BED?

never less than once a week more than daily
once a week once a week

HOW MANY TIMES HAVE YOU SEXUALLY TOUCHED ANOTHER PERSON?

never less than
once a week $\quad$ once a week more than daily

HOW MANY TIMES HAS ANOTHER PERSON SEXUALLY TOUCHED YOU?

never less than once a week more than daily
once a week once a week 
DURING THE LAST FOUR WEEKS:

HOW MANY TIMES HAVE YOU EXPERIENCED SEXUAL INTERCOURSE?

never less than
once a week. once a week $\begin{aligned} & \text { more than daily } \\ & \text { once a week }\end{aligned}$

HOW MANY TIMES HAVE YOU TOUCHED YOURSELF FOR SEXUAL PLEASURE?

never less than
once a week $\quad$ once a week $\begin{aligned} & \text { more than daily } \\ & \text { once a week }\end{aligned}$

HOW MANY TIMES HAVE YOU EXPERIENCED SEXUAL CLIMAX (ORGASM)?

never less than
once a week $\quad$ once a week $\begin{aligned} & \text { more than } \\ & \text { once a week }\end{aligned} \quad$ daily

DO YOU CURRENTLY HAVE A SEXUAL PARTNER(S)?

yes no

IF SO, IS YOUR SEXUAL PARTNER(S)...

male female.

REGARDING YOUR PRESENT AMOUNT OF SEXUAL ACTIVITY, HOW MUCH DO YOU DESIRE?

less same amount more

BETWEEN THE AGES OF 30 AND 50 HOW OFTEN DID YOU ENGAGE IN SEXUAL ACTIVITY?

$\begin{array}{llll}\text { never less than } & \text { once a week } \quad \begin{array}{l}\text { more than } \\ \text { once a week } a \text { week }\end{array} & \end{array}$


HERE ARE SOME QUESTIONS ABOUT SEXUAL ACTIVITY WHOSE ANSWERS DIFFER FROM PERSON TO PERSON. WOULD YOU READ EACH QUESTION AND CIRCLE THE ANSWER WHICH MOST ACCURATELY REFLECTS YOUR EXPERIENCE? PLEASE BE SURE TO ANSWER EVERY QUESTION ON THE LIST.

1. DURING THE LAST FOUR WEEKS, HOW OFTEN HAVE YOU BEEN PLEASURABLY TOUCHED BY ANOTHER PERSON?

never less than once a week more than daily once a week once a week

2. DURING THE LAST FOUR WEEKS, HOW OFTEN HAVE YOU TOUCHED ANOTHER PERSON FOR PLEASURE?

never less than once a week more than daily once a week once a week

3. DURING THE LAST FOUR WEEKS, HOW MANY TIMES HAVE YOU AND ANOTHER PERSON HUGGED?

never less than once a week more than daily once a week once a week

4. DURING THE LAST FOUR WEEKS, HOW MANY TIMES HAVE YOU AND ANOTHER PERSON KISSED?

never less than once a week more than daily once a week once a week

5. DURING THE LAST FOUR WEEKS, HOW MANY TIMES HAVE YOU AND ANOTHER PERSON CUDDLED IN BED?

never less than once a week more than daily once a week once a week

6. DURING THE LAST FOUR WEEKS, HOW MANY TIMES HAVE YOU SEXUALLY TOUCHED ANOTHER PERSON?

never less than once a week more than daily
once a week


7. DURING THE LAST FOUR WEEKS, HOW MANY TIMES HAS ANOTIEER PERSON SEXUALLY TOUCIIED YOU?

$\begin{array}{llll}\text { never less than } & \text { once a week } & \text { more than } \\ \text { once a week } & & \text { once a week }\end{array}$

8. DURING THE LAST FOUR WEEKS, HOW MANY TIMES HAVE YOU EXPERIENCED SEXUAL INTERCOURSE?

$\begin{array}{llll}\text { never less than } & \text { once a week } & \begin{array}{l}\text { more than } \\ \text { once a week }\end{array} & \text { daily } \\ \text { once a week } & & \end{array}$

9. DURING THE LAST FOUR WEEKS, HOW MANY TIMES HAVE YOU TOUCHED YOURSELF FOR SEXUAL PLEASURE?

$\begin{array}{ll}\text { never ons than a week } & \begin{array}{l}\text { more than } \\ \text { once a week aily }\end{array}\end{array}$

10. DURING THE LAST FOUR WEEKS, HOW MANY TIMES HAVE YOU EXPERIENCED SEXUAL CLIMAX (ORGASM)?
never less than once a week more than daily once a week once a week

11. DO YOU CURRENTLY HAVE A SEXUAL PARTNER(S)?

yes no

12. IF SO, IS YOUR SEXUAL PARTNER(S) . .

male female

13. REGARDING YOUR PRESENT AMOUNT OF SEXUAL ACTIVITY, HOW MUCH DO YOU DESIRE?

less same amount more

14. BETWEEN THE AGES OF 30 AND 50, HOW OFTEN DID YOU ENGAGE IN SEXUAL ACTIVITY?

never less than daily
once a week $\quad$ once a week $\begin{aligned} & \text { more than } \\ & \text { once a week }\end{aligned}$ 
* 15. BETWEEN THE AGES OF 30 AND 50, HOW MUCH DID YOU ENJOY SEXUAL ACTIVITY?

$$
\text { not at all some alot }
$$

(*This question was accidentally omitted in the final study due to clerical error.) 


\section{APPENDIX D}

\section{PERSONAL VIGNETTES}

Three general observations were made by the researchers regarding the characteristics of the participants in this study: the desire to be useful, to explain and/or justify answers, and slow response time.

1) The sample seemed to need to be needed and feel useful, and responded to participating in this survey as a way of contributing themselves in a worthwhile manner. When they had trouble understanding what was asked of them, or in understanding the questions, they seemed disappointed in themselves since they had a sense of obligation to do well in their part of the research. All of these participants took their roles seriously as part of the survey, and tried hard to fulfill them to the best of their ability and circumstance.

2) When participants had conversations with researchers while filling out the questionnaire, they explained and/or justified their answers to the researchers. They were often told that explanations were not necessary, but they of ten continued anyway.

3) Generally, all participants read the questionnaire more slowly than the researchers had anticipated.

There were additional unanticipated issues associated with conducting the study. The following observations were noted as problems in administration of the questionnaire to the whole group:

1) The room was too small to afford privacy which forced people to sit so close to one another that answers could be seen by fellow participants. Adequate allowance for wheelchaj.rs was not made which further contributed to the crowded conditions in the room. 
2) The close proximity of seating arrangements allowed people to visit with each other, and discuss the questionnaire during its administration.

3) Information and instructions were not received clearly when given to the group simultaneously. This necessitated giving instructions on an individual basis. It was found that directions were better received when eye contact was made, speech was slowed, and simple concrete language was used, eliminating abstract concepts and professional jargon.

Situations and circumstances varied with individual participants and necessarily affected their responses on the questionnaire. These problems were unanticipated by the researchers and included the following observations and interactions.

Four people had difficulty seeing well enough to read the questionnaire and required assistance. This meant that a researcher read the questions aloud to the individual participant, which was often accompanied by discussion or explanation. Also, one participant from a foreign country could not read the questionnalre because of her inability to read English and asked for assistance from a researcher.

One man had Parkinson's disease and because of palsy in his hands was unable to mark the questionnaire. He asked that a researcher mark the questionnaire for him as he pointed to the answer he selected.

Most participants had some loss of hearing and were unable to follow the directions given to the group as a whole, necessitating instructions being given on an individual basis. 
The memory of personal losses was stimulated by the questions for some participants, resulting in further reminiscence and their need to share these reactions with researchers through extended conversations.

Consulting with the social worker of the agency upon completion of the research, it was learned some participants did not disclose information regarding their intimate relationships on the questionnaire. One lady in particular stated she did not think she could answer the questions and did not believe she had anything to contribute. She went on to describe her relationship with another patient as being only friends with an occasional kiss and disclaiming any kind of sexual relationship. She said, "He respects me and has not taken advantage of me." The social worker later reported that this same woman had come to her for sexual counseling in her relationship with this boyfriend. One woman participant cried during the administration of the questionnaire and when asked by the researcher if she wanted to continue, insisted that she wanted to participate. When asked if the questions were bothering her, she said they did not bother her, that she had no relationships. She attributed her sadness to being unable to see the questions well enough to read them for herself and was embarrassed at her loss of eyesight. Later on, the social worker reported that this woman had often been observed reading books during her free time.

Some participants related to the researchers that the questions were too personal, were an invasion of their privacy and had no relevance to their current life situations. Two women, both widows in 
wheelchairs, felt both of these conditions made their participation useless, and resented being asked about their sex life. They refused to complete the questionnaire.

One married couple participated in the study and the man was heard telling his wife that their answers needed to match. The woman later commented to a researcher that she had not had sex with her husband since they were first married because they had discovered early in their marriage that she was unable to bear children. She went on to say, "but he has been very good to me over the years".

The husband of this pair commented to another researcher, when handing in his questionnaire, "Now you can see what kind of a man I am", accompanied by a grin. The questionnaires did not match.

When researchers discussed an compared their experiences with participants, the following problems were noted pertaining to the questionnaires.

1) The cover sheet containing the demographic questions was noted to be difficult on question $\#^{2}$ for anyone whose education system was not applicable to the categories presented; for example, those educated in a foreign country or an alternative education program.

2) Question \#5 was confusing for one participant who was in her nineties, since she felt there was no age category appropriate for her.

3) The questionnaire on life satisfaction (the LSIZ) was confusing on items $J$ and $M$ for many participants. Researchers were of ten asked to clarify the meaning of those two questions, since the wording seemed to confuse their intended response. 
4) On the sexual activicy questionnaire, there were problems with questions $\|_{1}$ and $\# 2$, specifically with the term "pleasureably touched". Some participants were only able to relate the term "pleasurably" to specific categories or incidents:

A. Foreplay to sexual activity.

B. Sexual activity,

C. One woman reported the only time she was pleasureably touched was by her father when he ruffled her hair as a little girl.

D. One woman wanted to know if holding a baby counted as touching.

5) The term "touching" was confusing and many did not consider any hand-to-body touching that was part of their caretaking, or as greetings from relatives and friends. Another participant commented that she could not answer 非 2 because she had no way of knowing if the other person enjoyed it when she touched them--incerpreting the question differently than it was intended by its designers.

6) Questions $\# 3$ and $\|_{4}$ was responded to by one participant saying, "The only time I'm hugged or kissed is twice a month when my son comes to visit me." Many other participants answered with "never" interpreting the question as a sexual activity。

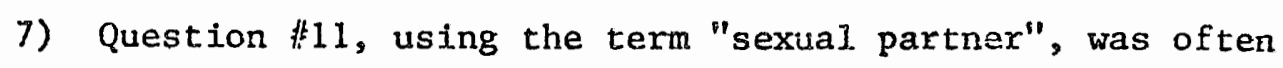
interpreted by this group as an ongoing relationship, mate, ox most often, as a marriage partner.

8) Questions $\|_{13}$ and $\|_{14}$ contained barriers in language. The questions were not simple and concrete enough for participants to answer. Many participants asked for clarifications from researchers regarding the meaning of these two question. 


\section{APPENDIX E}

\section{INFORMED CONSENT}

I hereby agree to participate in the study on aging by the students in the School of Social Work of Portland State University. I have been informed that my participation is voluntary and confidential. I have also been informed that I can withdraw from this study at any time.

Signed

Date 